\title{
THE JUDGE'S ROLE IN OVERSEEING THE ARBITRATORS' WORK: IN THE OMANI AND EMIRATI MODEL

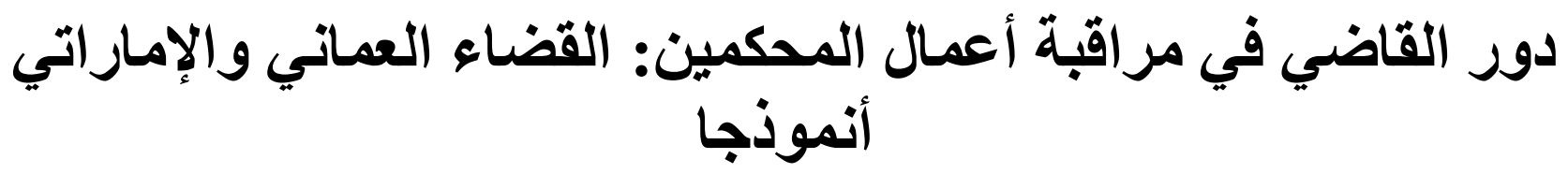

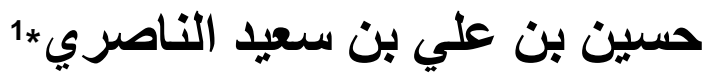

Al Nasseri Hussein Ali Said ${ }^{1 \star}$ and Mohamed Ibrahim Negasi ${ }^{2}$

${ }^{1}$ Ph.D. Candidate in Law at Ahmad Ibrahim Kulliyyah of Laws, International Islamic University Malaysia (IIUM): hu92955@icloud.com

${ }^{2}$ Assoc. Prof. Dr. at Ahmad Ibrahim Kulliyyah of Laws, International Islamic University Malaysia (IIUM): mohnegas@gmail.com

${ }^{*}$ Corresponding Author

\begin{abstract}
This descriptive, analytical study discusses the judges' role in monitoring the arbitrators' affairs, according to the Omani and Emirati judiciary. The problem arises; in many problems that arise over the judges' role in observing the work of arbitrators, as the Omani and Emirati legislator followed judicial oversight of both previous and subsequent arbitrators' work, with measures that permits the two laws to judicially interfere with the arbitrators' actions, whether that intervention is complementary, or for the judiciary to be obligated to intervene in cases approved by the legislator, which were brought in exclusively after the award of the arbitration. The research objectives are: to discuss the legal controls that govern the interference of the judiciary in forming the arbitration board. And a statement of the legal system that governs the response of members of the arbitral tribunal, and the extent of the judiciary's authority in the arbitration board's participation in the arbitration litigation procedures. The comparative descriptive analytical method was adopted. The findings revealed that: The Omani and Emirati legislators granted freedom to the parties to arbitration, in the formation of the arbitration panel, to choose the arbitrator to separate the discounts. The arbitration panel has a specific privacy provision within the framework of the arbitration law. The role of the judiciary in activating the negative impact of the arbitration agreement is not from the public order, but rather depends on one of the parties filing a case.
\end{abstract}

Keywords: Arbitration, judge's role, oversight.

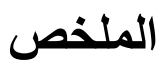

تناقش هذه الدراسة الوصفية التحليلية دور القاضي في مراقبة أعمال المحكمين، وفق القضاء العماني والإمار اتي. تبرز المشكلة؛ بوجود العديد من الإشكاليات التي تثار على دور القاضي في 
مر اقبة أعمال المحكمين، فالمشرع العماني والإمار اتي، اتبعا الرقابة القضائية لأعمال المحكمين

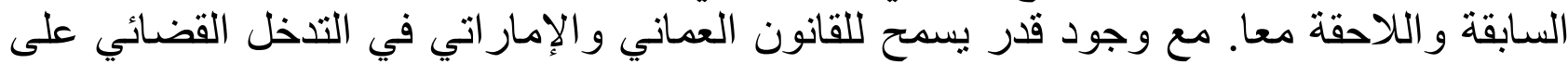

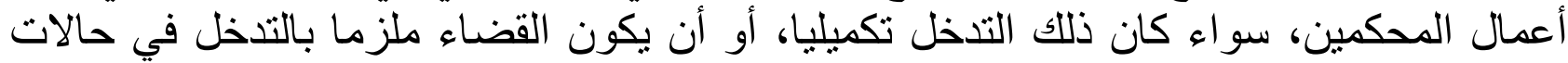

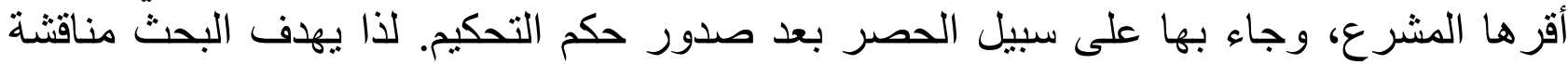

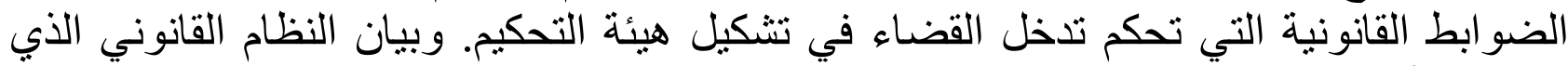

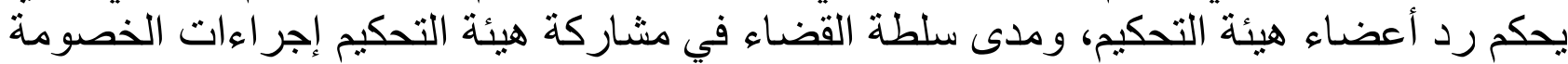

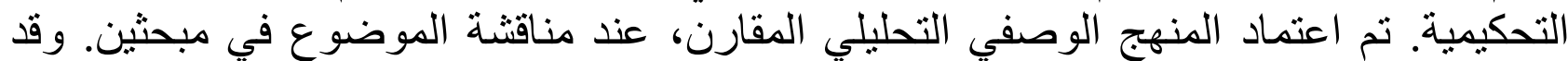

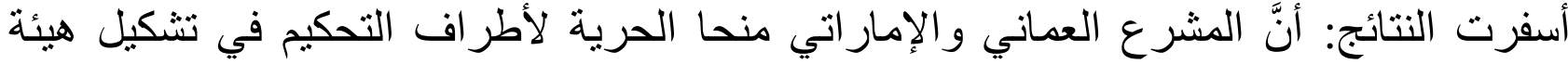

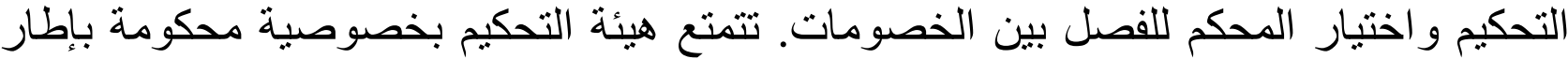

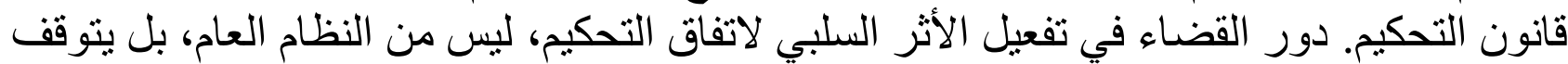

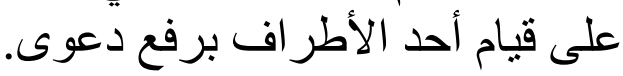
كلمات مفتاحية: التحكيم، دور القاضي، المر اقبة.

\section{المقدمة}

إن النمو الكبير للتجارة وتشابك المصالح الاقتصادية المشتركة بين الدول والأفر اد والثورة العلمية

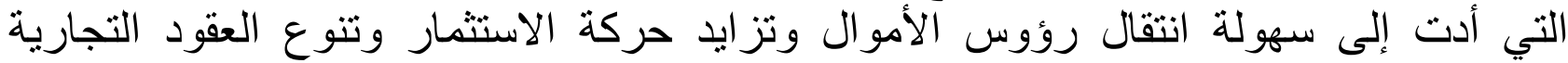

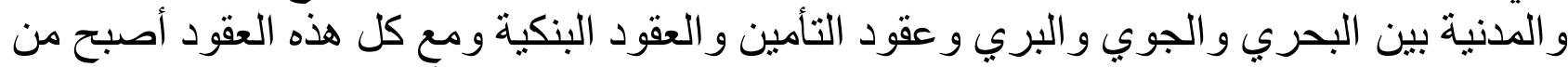

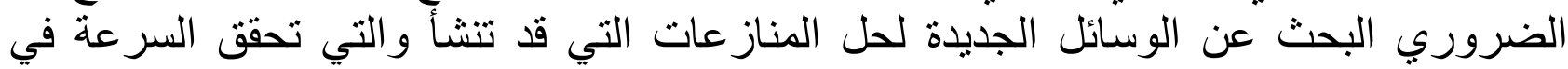

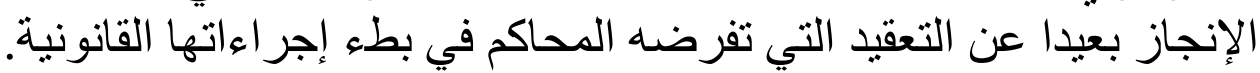
وفي ظل ازدياد أهمية التحكيم في دول العالم مما يفرض على الوا اقع تعدد جنسيات المتعاقدين

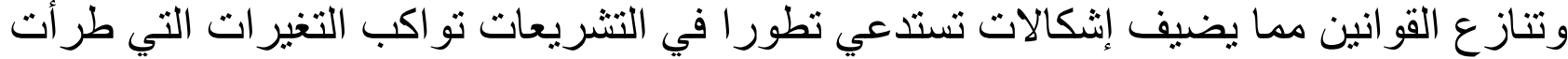

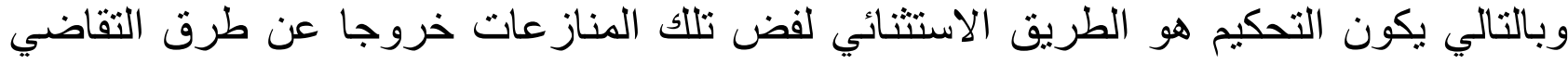
العادية وهو طريق استثنائي رسمه القانون لحنل مناز عاتهم.

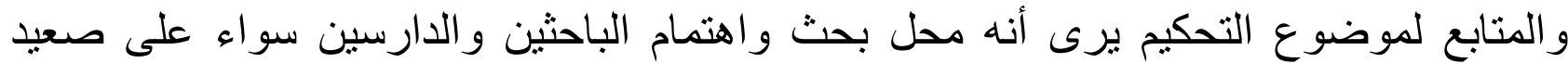

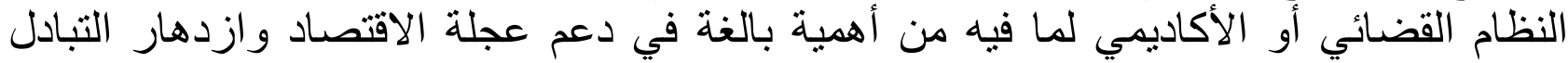

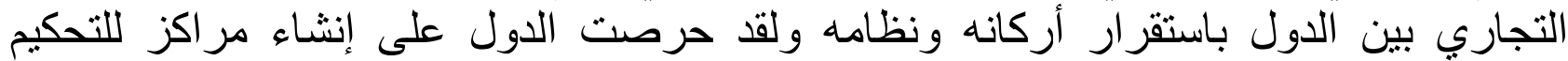

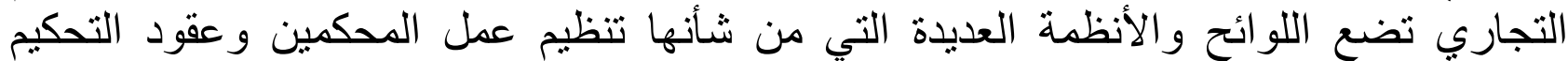
وتشكيل هيئات تحكيم و التي بدور ها تلخفيف العبء التئ الملقى على كاهل القضاء.

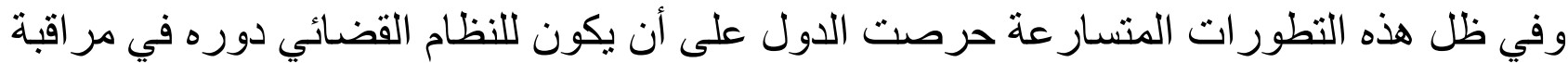

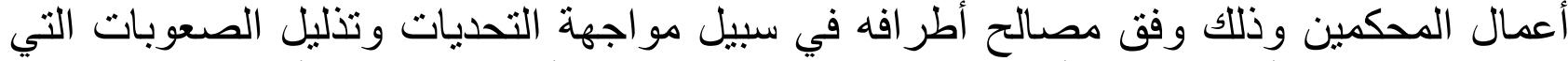

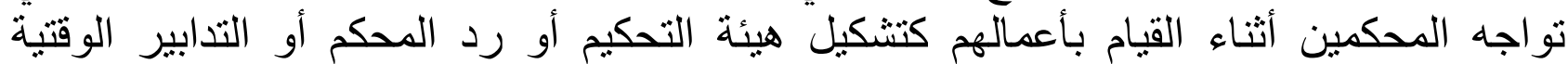

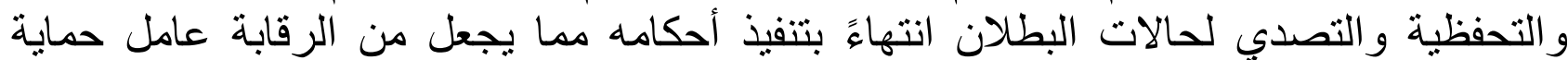

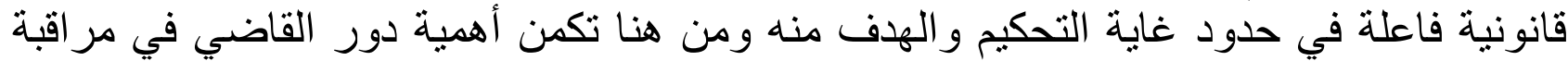

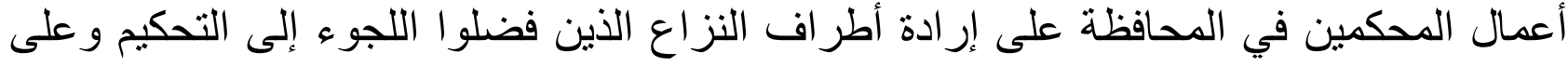




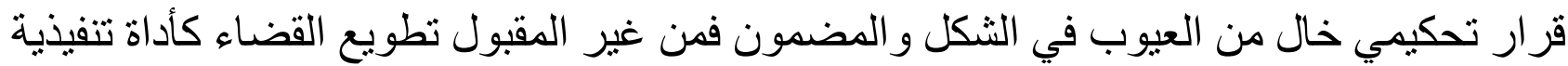

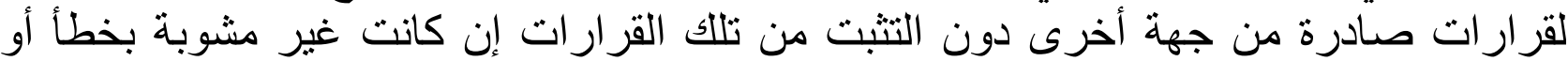

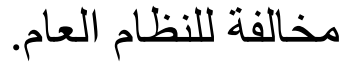

ومما لا شك فيه أن الآراء الفقهية اختلفت حول طبيعة دور القاضي في مر اقبة أعمال المحكمين

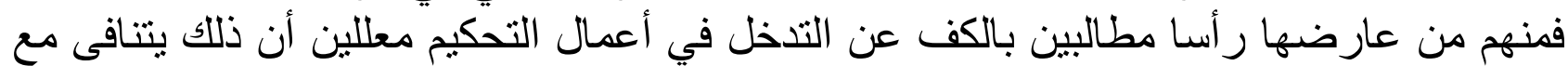

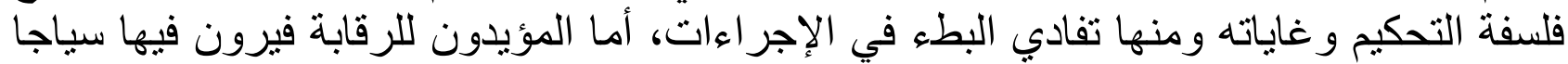

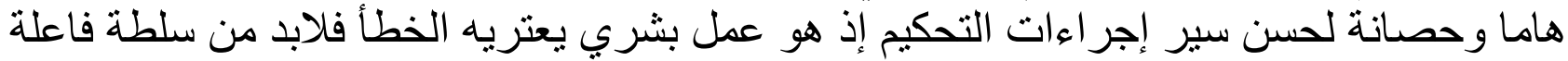

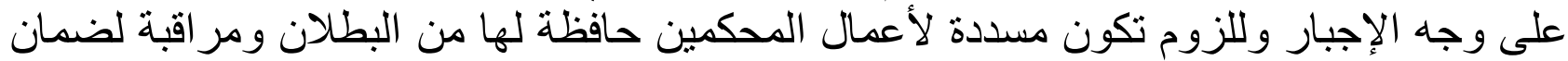

ت ت تقبذ قر ارتها.

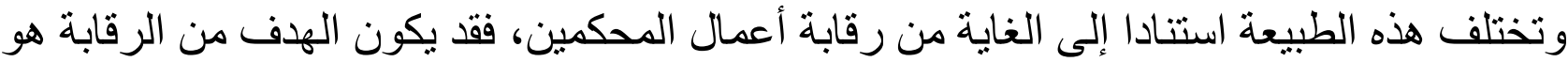

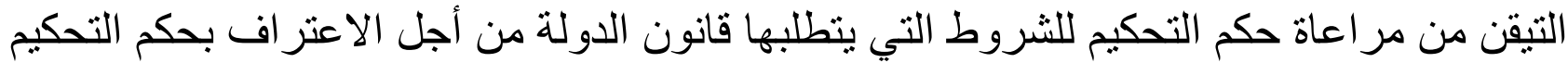

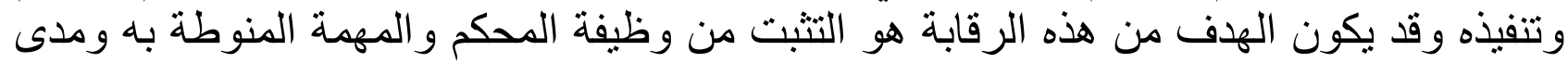
احتر امه للقو اعد القانونية سواء المتصلة باتفاق التحكيم ذاته أو بإجر اءوات التهن التحكيم تفاديا لحالات

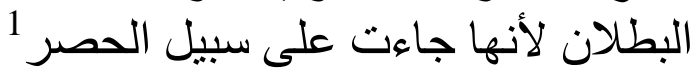

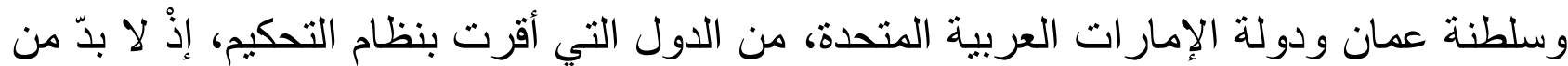

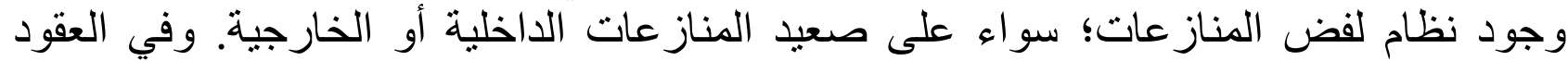
الأخيرة شهدت الدولتان حركة انتعاش في جميع الأنشطة التجارية مما أدى إلى جذب التب المستثمرين الأجانب للاستثمار فيهما.

وستتناول هذه الدر اسة موضوع دور القاضي في الرقابة على أعمال المحكمين وفقا لنصوص النصان

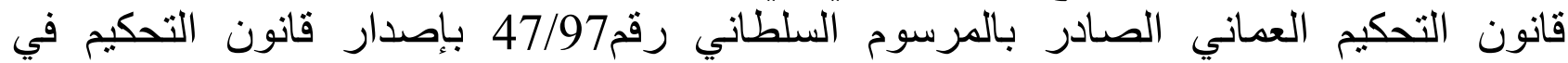

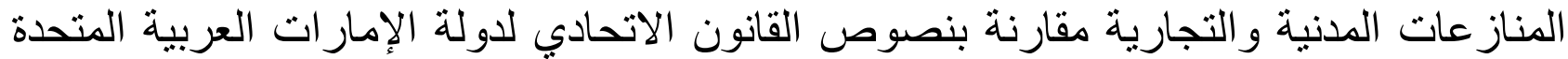

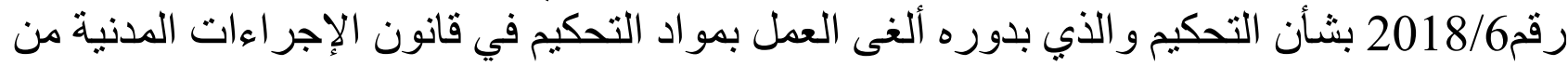

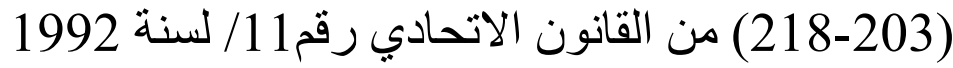

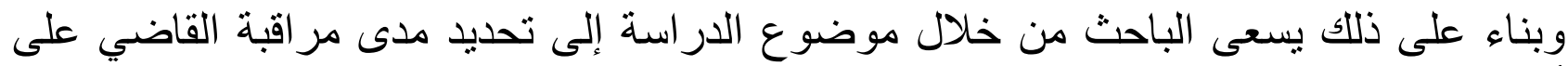

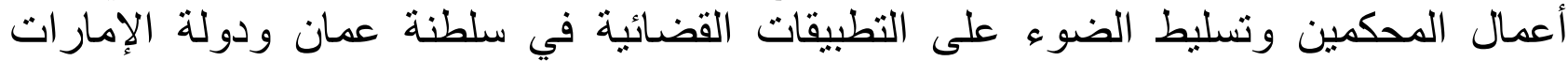

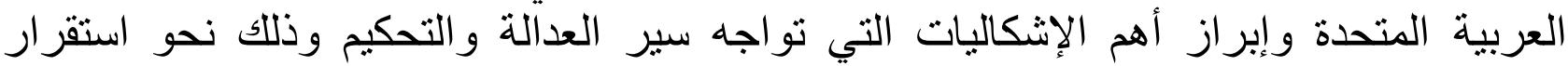

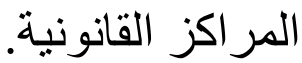

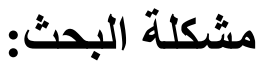

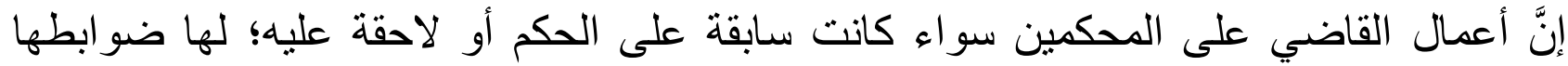

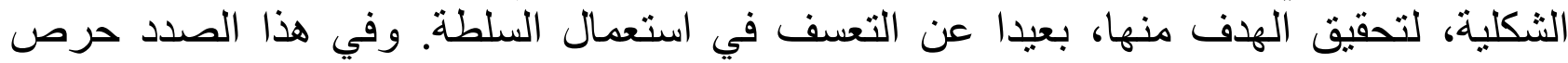

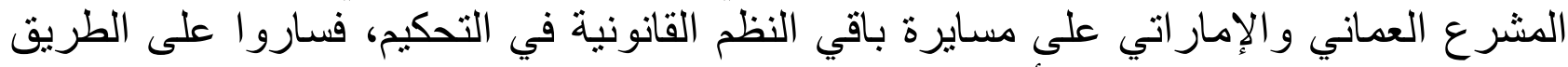
المزدوج لتشمل الرقابة القضائية أعمال المحكمين السابقة والني الناحقة معا. لنرى بعد ذلك لأي مدى يسمح القانون العماني والإماراتي في التدخل القضائي على أعمال 1الحداد، حفيظة السيد. 2003. الرقابة القضائية على أحكام المحكمين بين الازدواجية والوحدة. دار الفكر الجامعي، ص7 


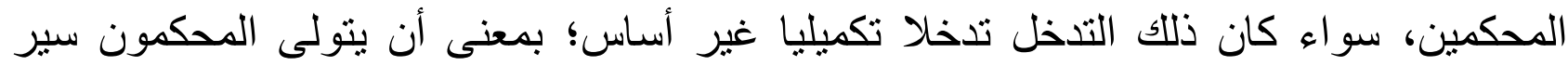

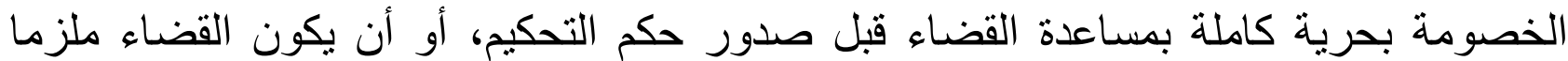

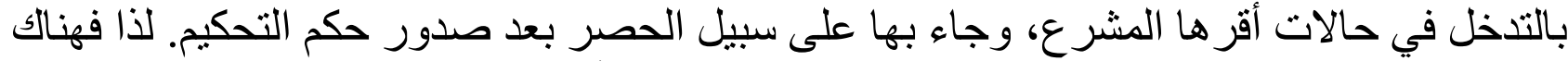
العديد من الإشكاليات التي تثار على دور القاضي في مر اقبة أعمال المحكمين.

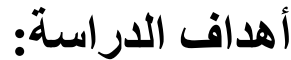

أ. مناقثنة الضو ابط القانونية التي تحكم تدخل القضاء في تشكيل هيئة التحكيم. ب. بيان النظام القانوني الذي يحكم رد أعضاء هيئة التحكيم، ومدى سلطة القضاء في مشاركة هيئة التحكيم إجر اءات الخصومة التحكيمية.

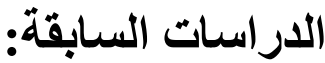

1-دراسة بعنوان" بطلان اتفاق التحكيم في القانون العماني دراسة مقارنة" وفاء بنت عبدالله

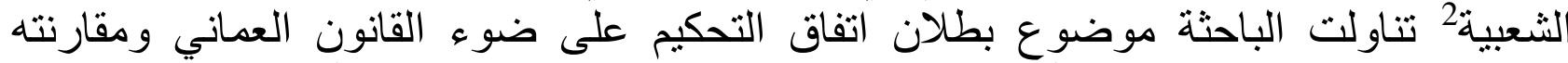

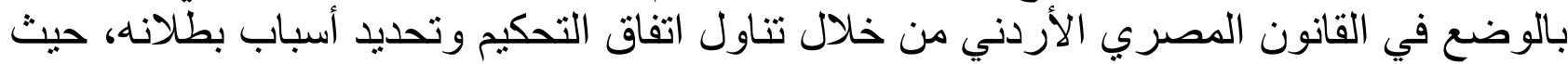

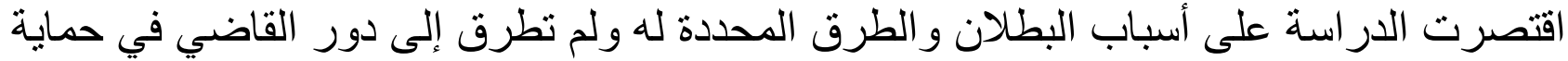

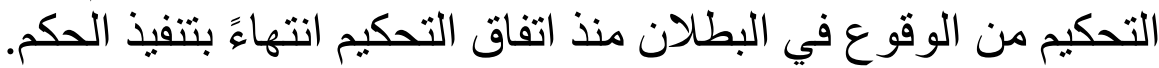

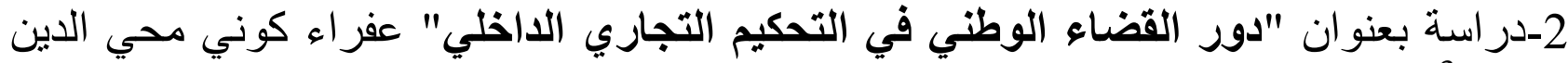

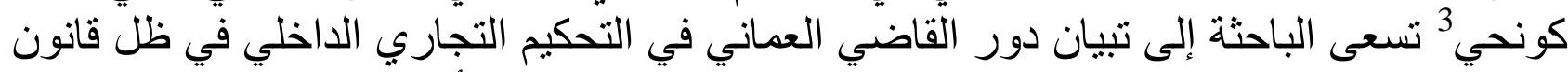
التحكيم في المنازعات المدنية والتجارية العماني صدور حكم التحكيم او بعد صدور الحكم على مرحلتين كما نوضيح الدور الغير مباثر لفئر للقضاء

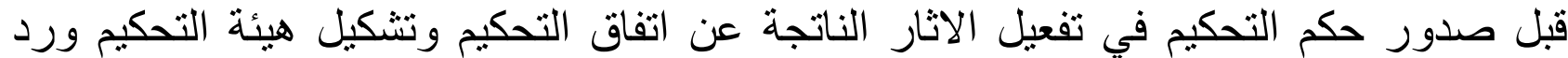

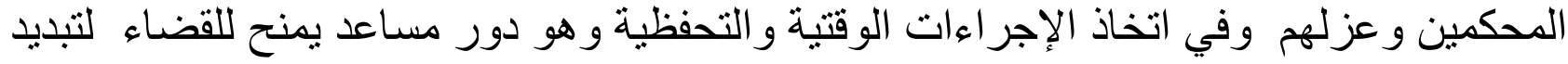

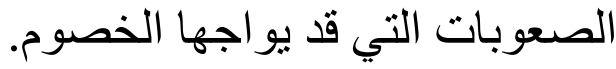

3-در اسة بعنوان "رقابة القضاء على ميعاد التحكيم" مروان محمد سلامة المحاميدثنتاول الباحث

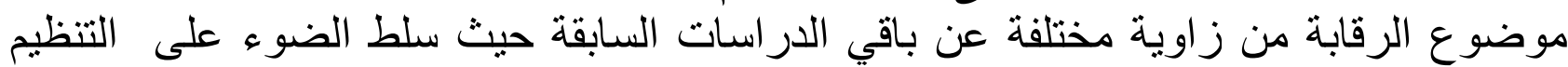

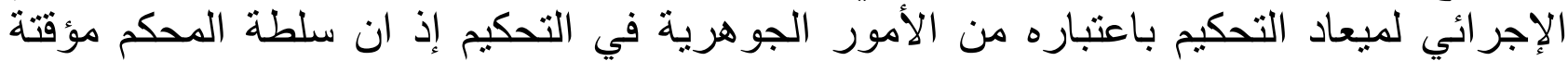

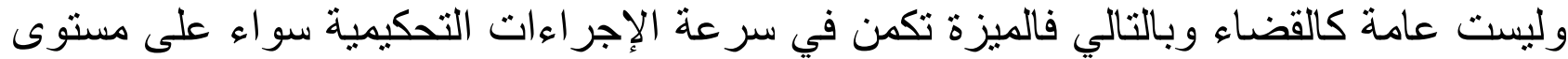

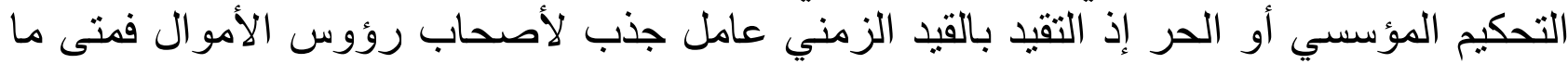

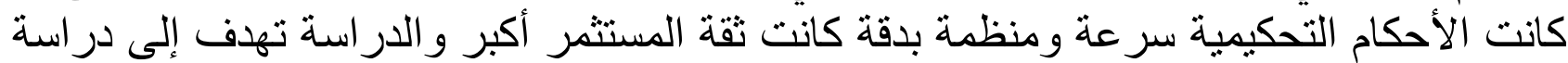

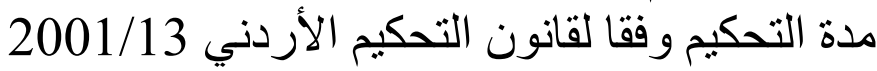
4-دراسة بعنوان "الرقابة القضائية على هيئة التحكيم: دراسة نظرية وفقا لقانون التحكيم

2 الثعيبية، وفاء بنت عبدالله، بطلان اتفاق التحكيم في القانون العماني (سلطنة عمان: جامعة السلطان قابوس، كلية الحقوق، بحث ماجستير غير منشور، 2014) 3 كونحي، عفر اء كوني محي الدين، دور القضاء الوطني في التحكيم التجاري الداخلي (سلطنة عمان: جامعة السلطان قابوس، كلية الحقوق، بحث ماجستير غير منشور ،2018) 4 المحاميد، مروان محمد سلامة، رقابة القضاء على ميعاد التحكيم(الأردن: جامعة الثرق الأوسط، كلية الحقوق، بحث ماجستير غير 


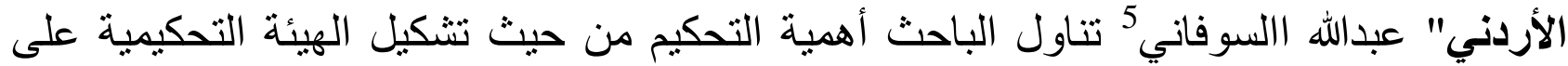

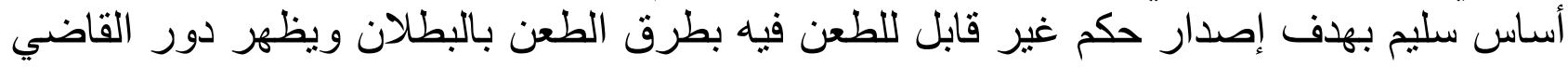

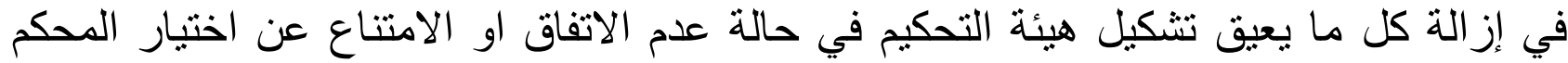

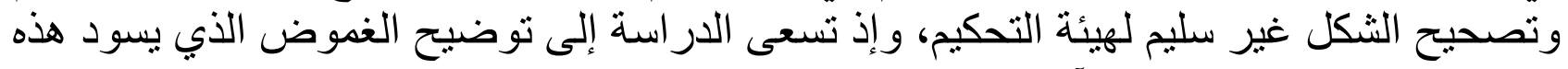

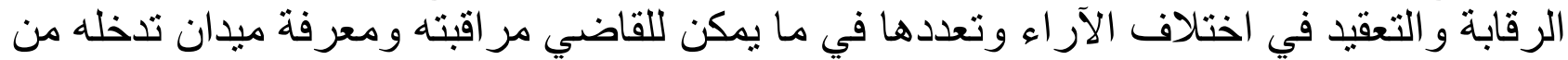
خلال التأويل الصحيح لأحكام القانون.

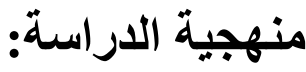

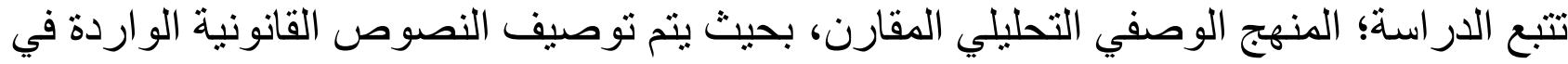

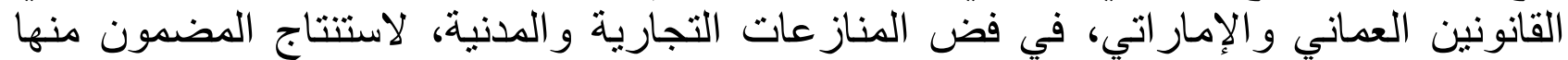

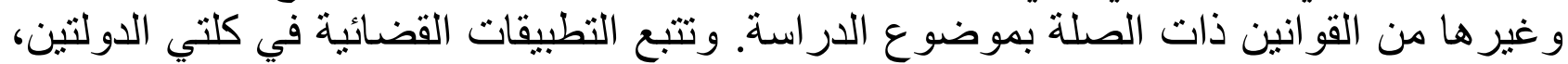

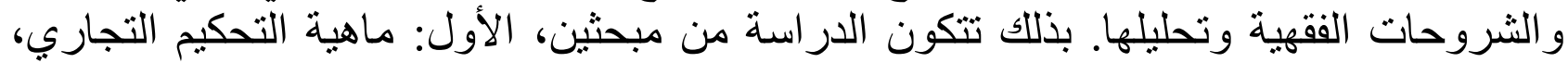
و الثاني: مرحلة ما بعد صدور حكم التحكيم.

\section{المبحث الأول: ماهية التحكيم التجاري}

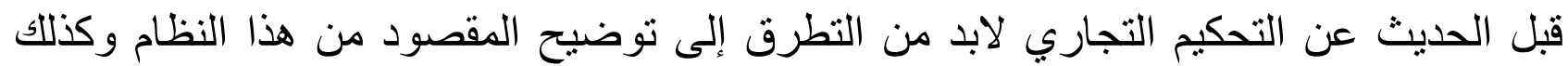

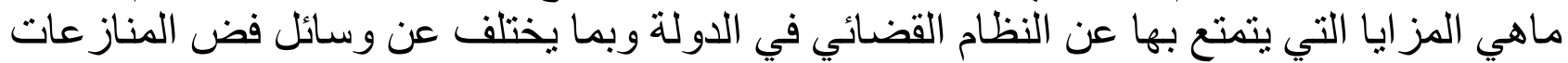

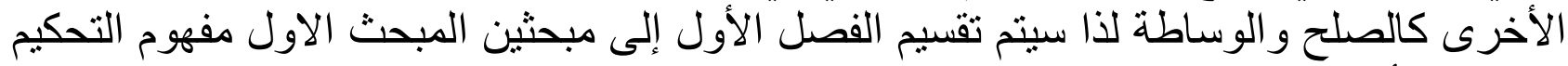

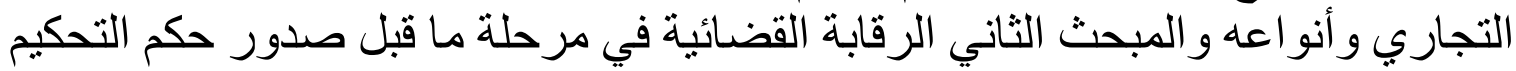

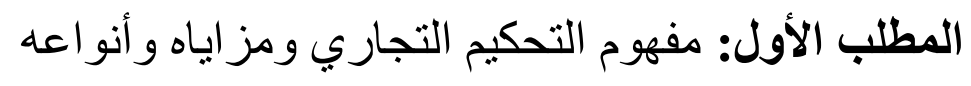

تعريف التحكيم لغة واصطلاحا: مهوم

لقد تتاول علماء اللغة تعريف التحكيم بقولهم: الفعلُ حكَّ بمعنى قضىى، وحاكمهاه بمعنى دعاه وخاصمه وحكمه في الأمر تحكيما بمعنى أمره أن بحكم فاحتكمُ

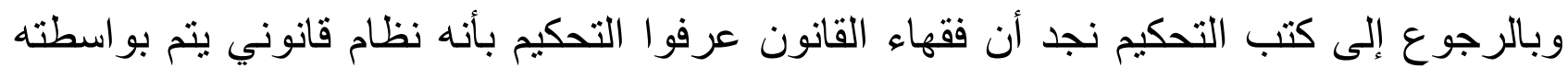

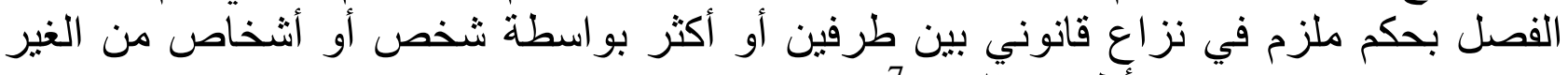

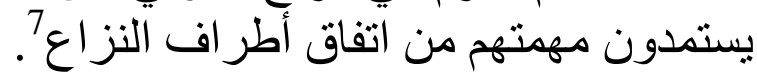

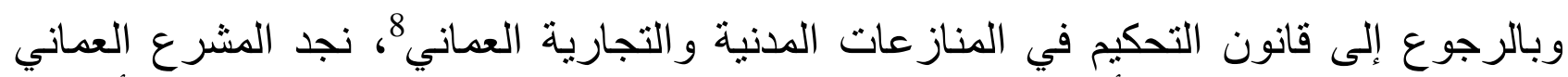

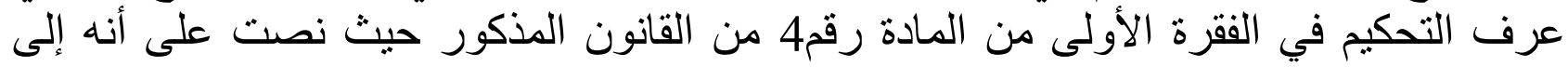

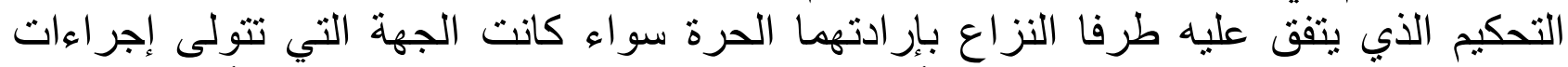

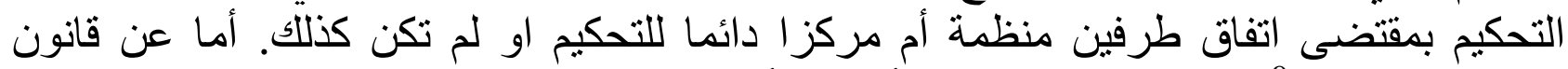
التحكيم الإمار اتي 9 الذي جاء في مادته الأولى؛ بأن التحكيم وسيلة ينظمها القاني لـانون يتم من خلالها

5 السوفاني، عبدالله خالد علي، الرقابة القضائية على هيئة التحكيم: دراسة نظرية وفقا لقانون التحكيم الأردني(الأردن: مجلة المنارة

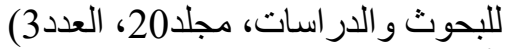

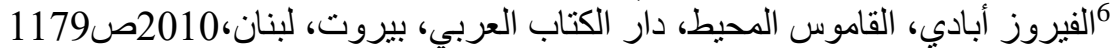

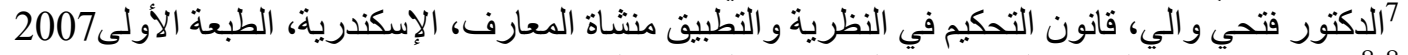

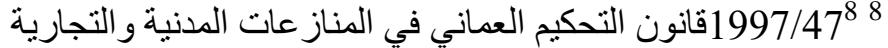
2018/6 قانون التحكيم الاتحادي الصادي 
الفصل بحكم ملزم في نزاع بين طرفين أو أكثر بو اسطة هيئة التحكيم بناء على اتفاق الأطر اف.

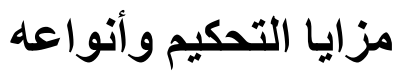
أولا: مزايا التحكيم

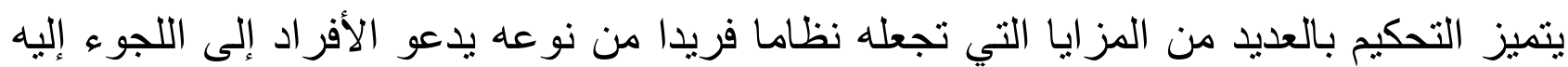

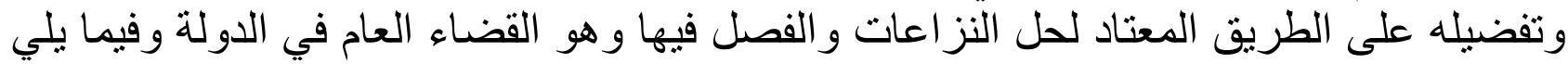

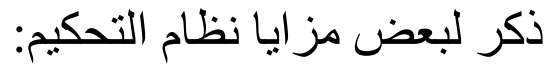

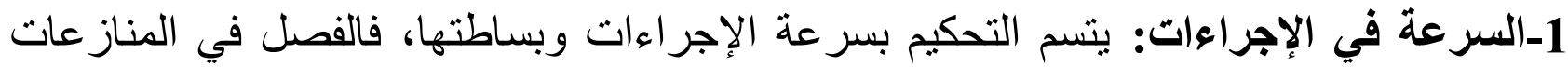

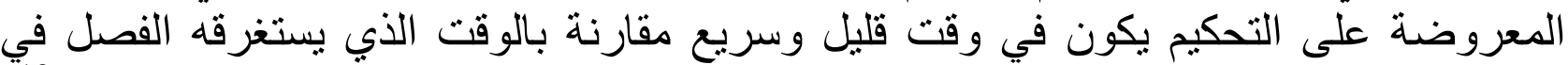

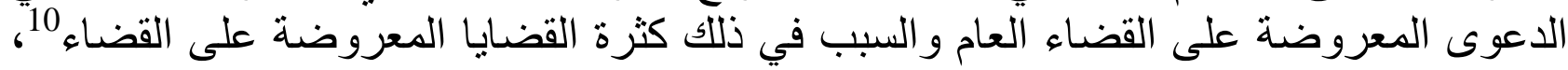

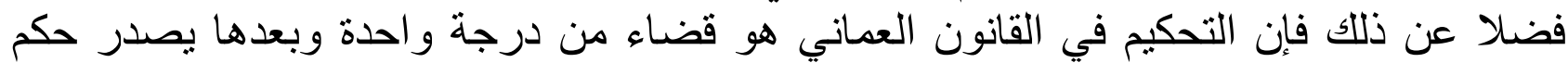

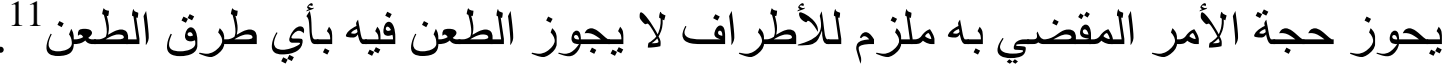

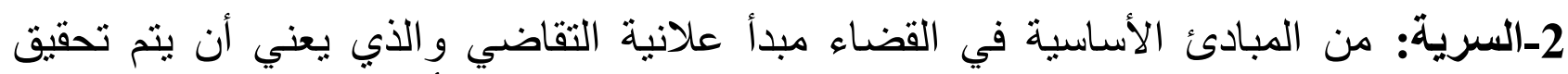

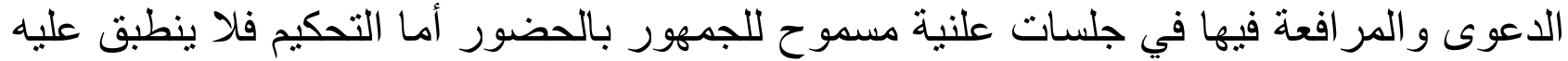
هذا المبدأ فجلساته سرية مقتصرة على الأطر اف و هيئة التحكيم و الحكم الذي تصدره هينة هيئة التحكيم

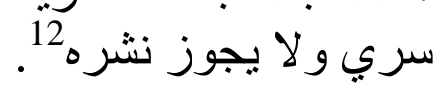

3-حرية الأطراف في نظام التحكيم: وكما هو معلوم ليس للأطر افت أبي سلطة في اختيار

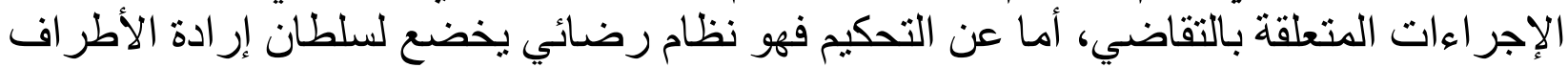

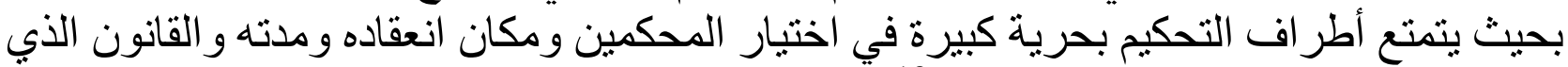

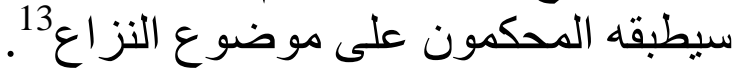

ثانيا: أنواع التحكيم: قسم فقهاء القانون التحكيم إلى أنواع عديدة، بحسب الزباء اوية التي ينظر إليها إلى التحكيم

1إلتحكيم الاختياري والتحكيم الإجباري: فالأصل في التحكيم أنه أمر اختياري يخضع لمطلق

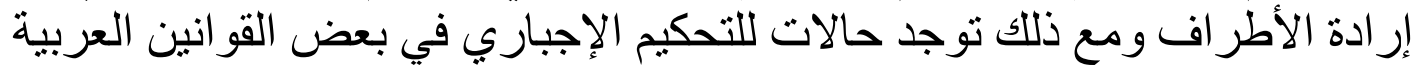

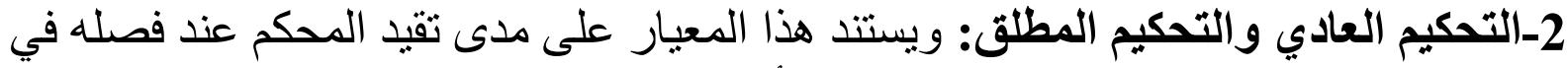

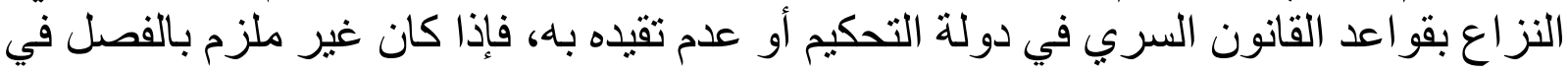

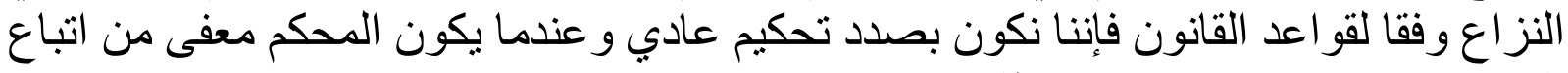
القانون فإننا نكون إز اء تحكيم مطلق.

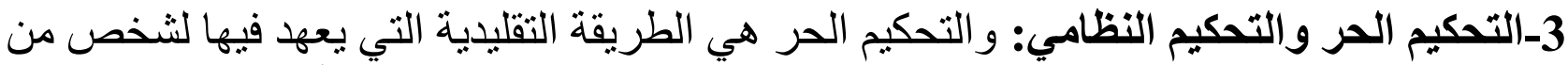

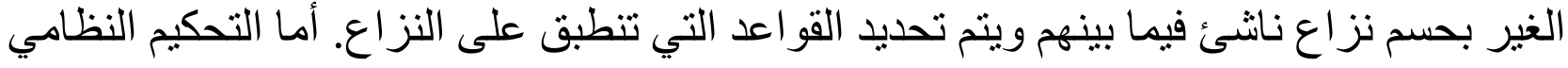

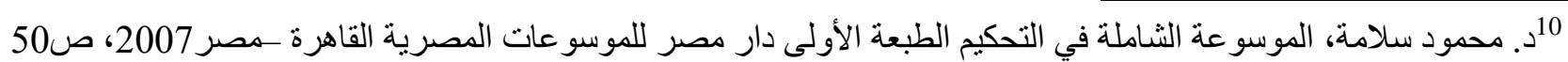

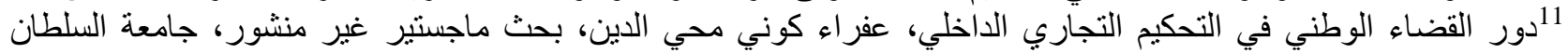

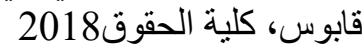

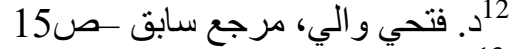

جمامحم بن حسن العسيري، الرقابة القضائية على التحكيم وفق النظام السعودي، رسالة ماجستير غير منشورة - كلية الحقوق،

جامعة القاهرة، مصر بن حند 
فيعهد فيه إلى هيئة أو منظمة.

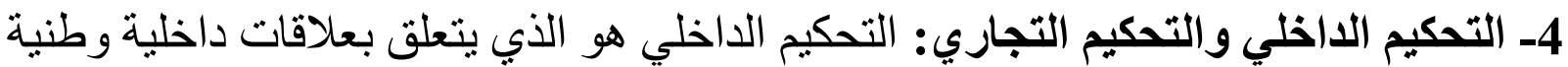

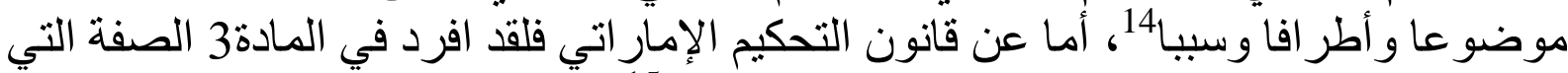

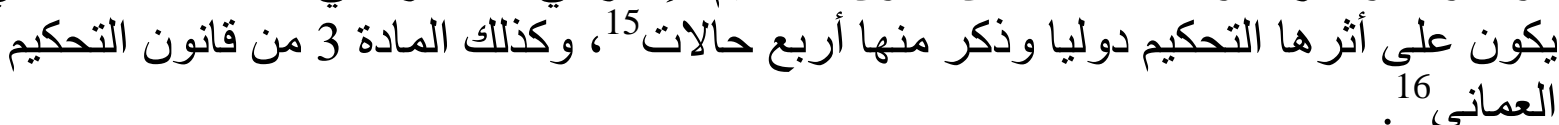

\section{المطلب الثاني: دور القاضي في مرحلة ما قبل صدور حكم التحكيم

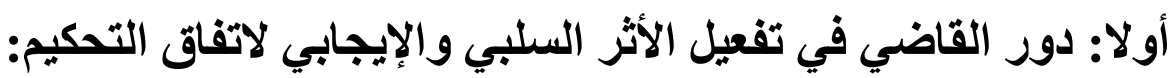

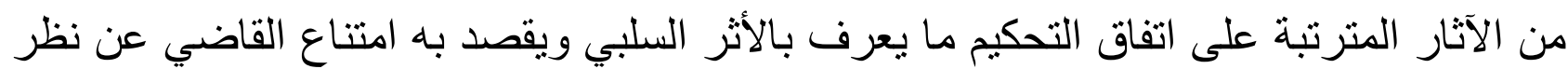

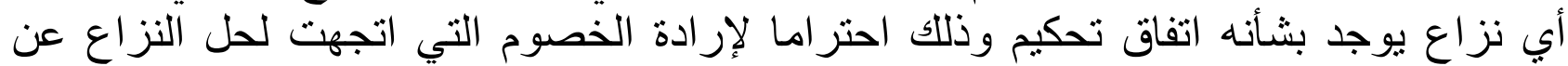

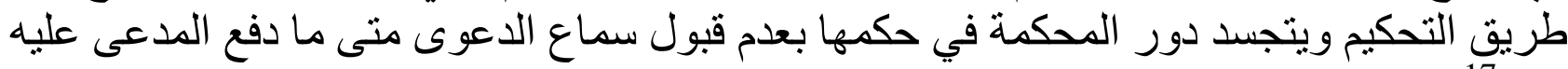
بذلك 17.

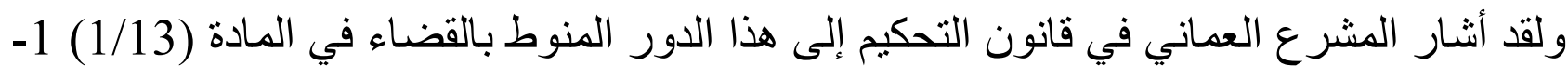

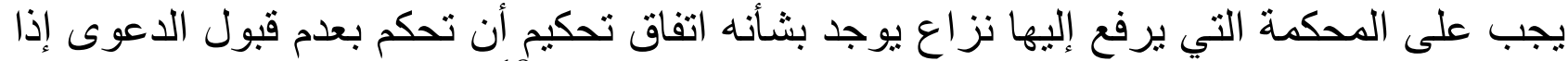

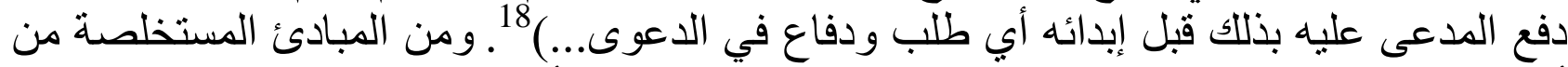

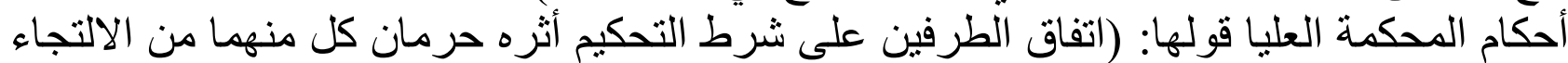

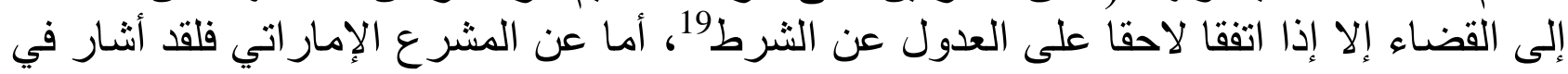

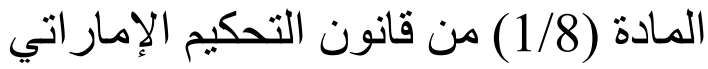

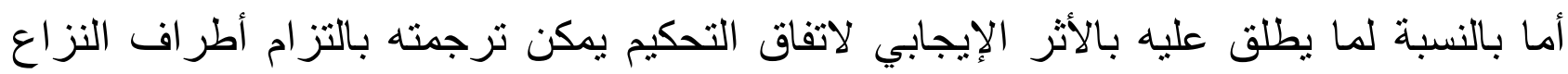

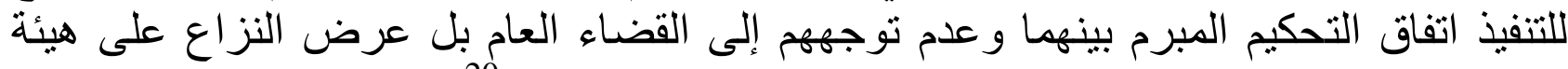

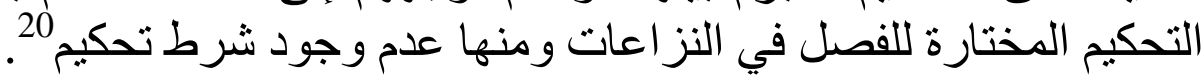
ثانيا: دور القاضي في تثكيل هيئة التحكيم: كثير ا ما يحاول أحد طرفي النزاع أو حتى أحد المحتكمين المختارين تعطيل عملية التحكيم بوقفه هئه

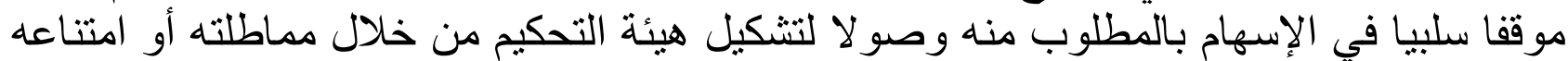

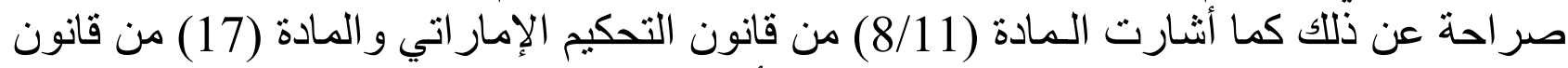

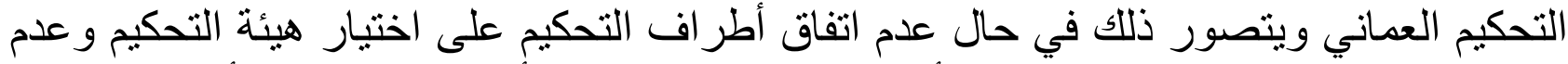

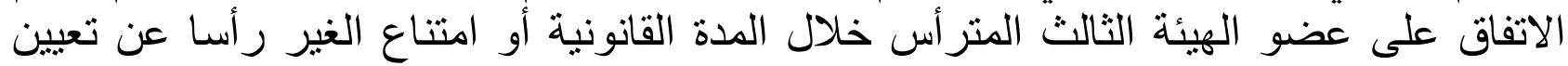

الإند. نبيل إسماعيل عمر، التحكيم في المواد الددنية والتجارية الوطنية والدولية، دار الجامعة الجديدة، الطبعة الثانية2005،

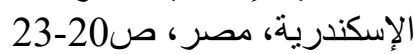
15 إقانون الندكيم الإمار اتي، مرجع سابق

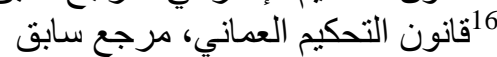

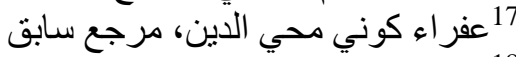

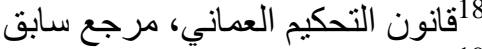

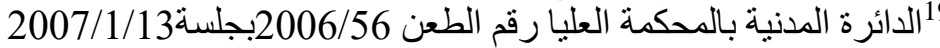

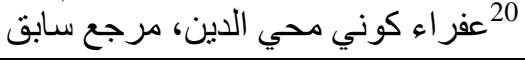


محكم 21 ويتصور ذلك في صورنين: الصورة الأولى: تعيين المحكم: وذللك على النحو التالي فئي

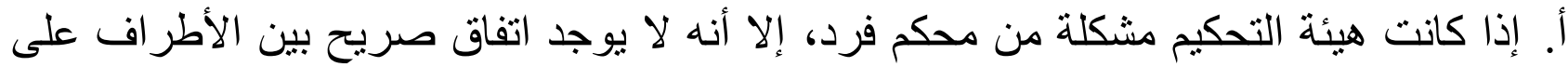

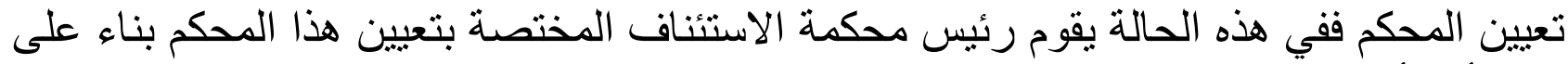
طلب أحد أطر اف التحكيم. تصني

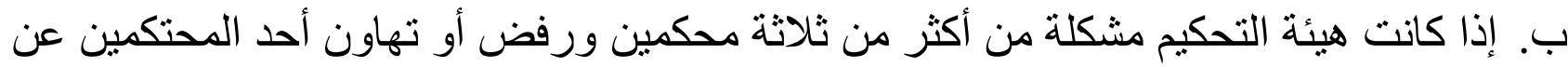

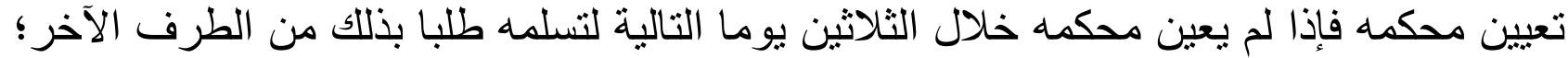

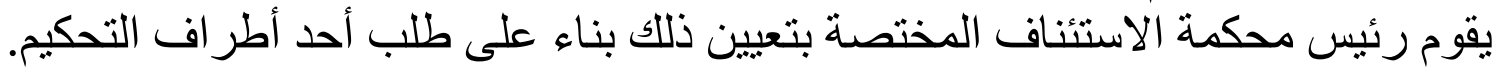

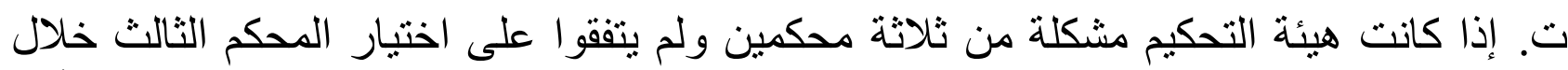

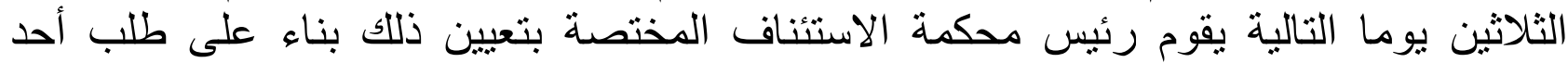
أطر اف التحكيم22.

الصورة الثانية: دور القاضي عند التخلف عن إجراء أو عمل لازم لاختيار المحكمين: عالجت

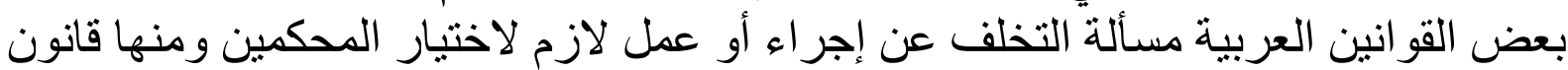

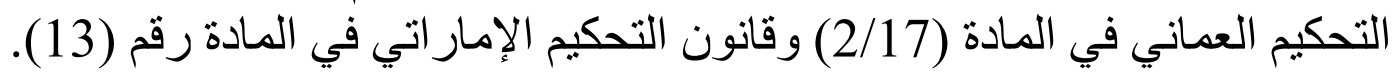

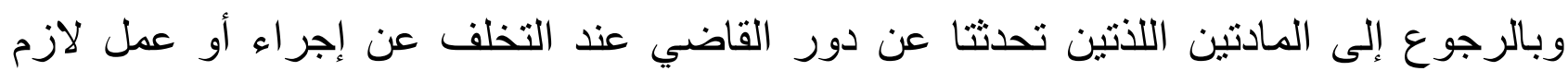

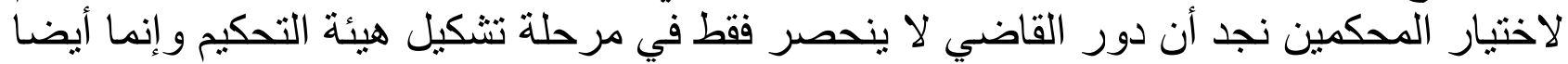

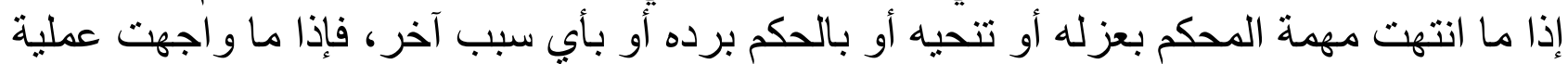

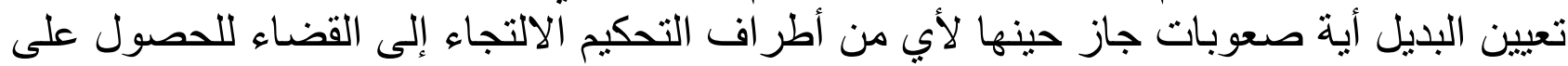

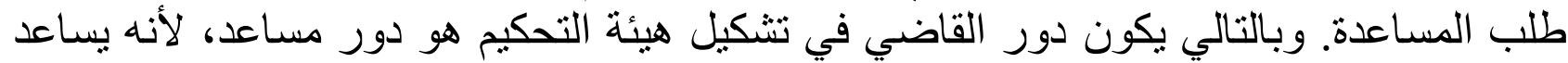

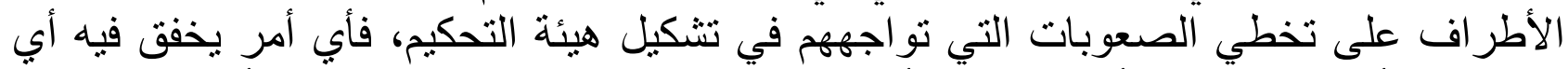

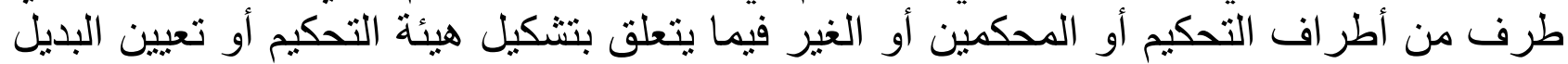

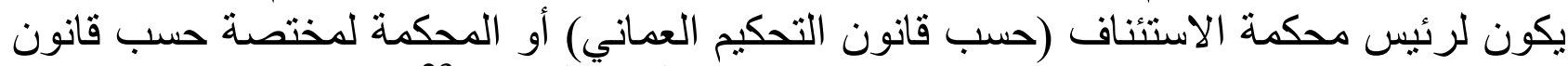

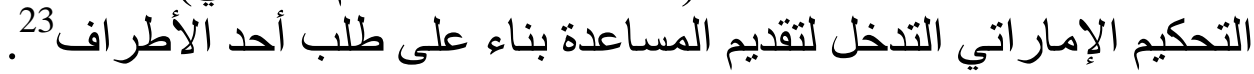

ثالثا: دور القاضي في رد المحكمين:

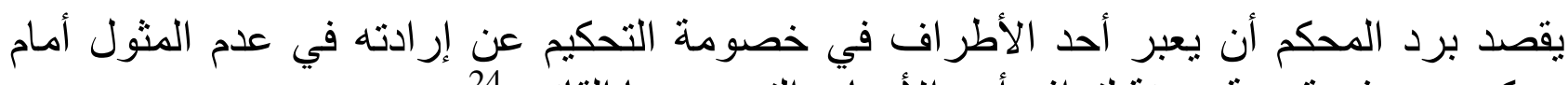

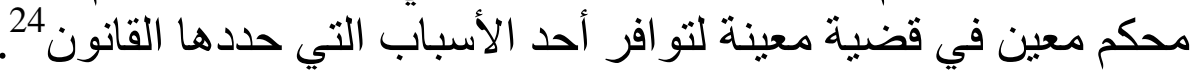

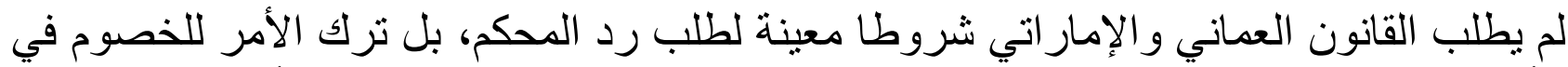

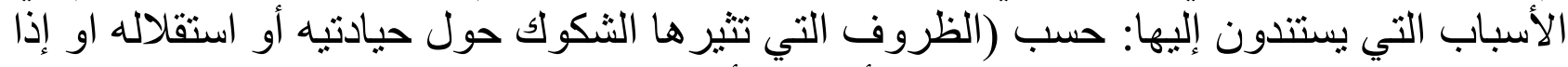
ثبت عدم توافر الثروط التي اتفقا عليها الأطر اف أو التي نص عليها هذا القانون) فهل وفقا في التها

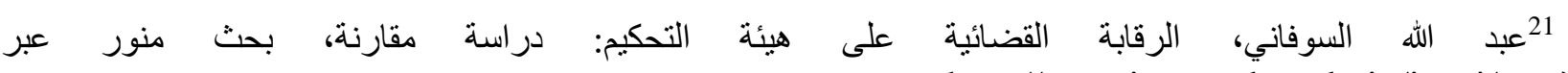

الإنترنت/http://repository.aabu.edu.jo/jspui الارلد. عامر فتحي البطانية، دور القاضي في التحكيم التجاري الدولي دراسة مقارنة، دار الثقافة بعمان - الأردن - الطبعة 
هذه الصياغة وتركا أمر الحياد والاستقلالية مرنا، بحيث ترك الأمر يرجع إلى تقدير القاضي أم المان

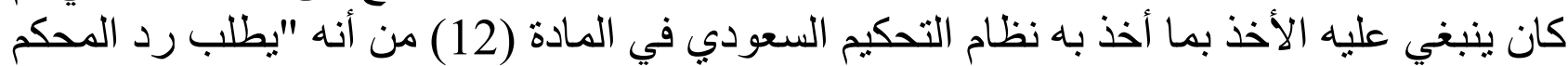

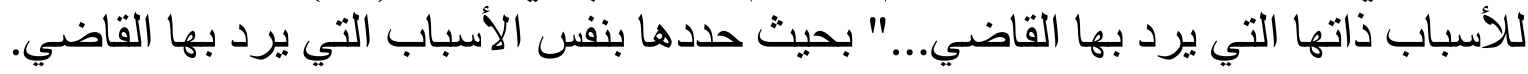

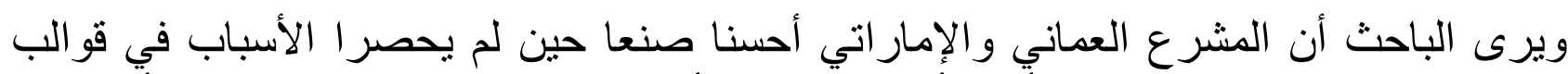

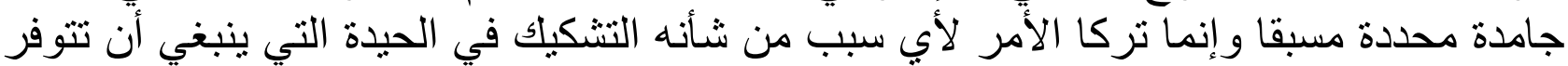
في المحكم. رابعا: تنحي المحكم وعزلكه: يقصد بالتنحي التصرف الإر ادي الذي يصدر من جانب المحكم في الحالة التي يستشعر فيها عجزه

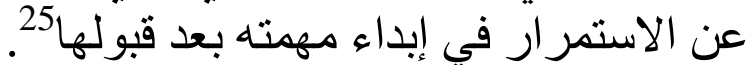

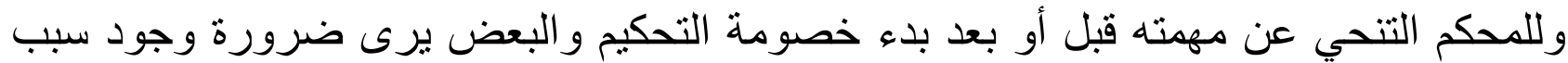

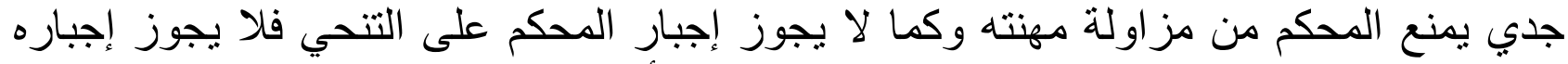

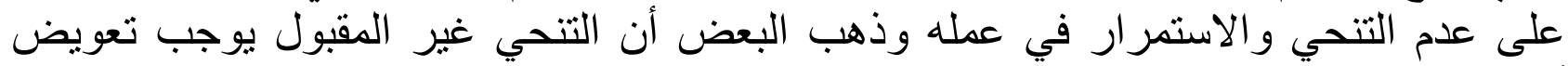
أطر اف التحكيم

أما عن العزل فهو مختلف عن التتحي فيجوز عزل المحكم وإن لم يكن موافقا على ذلك ويكون

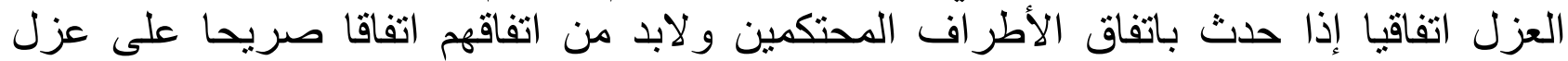

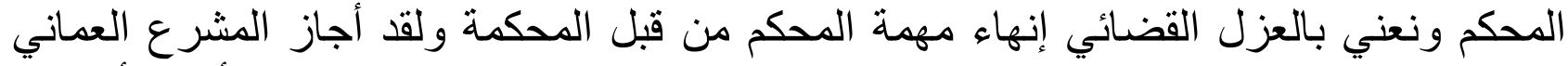

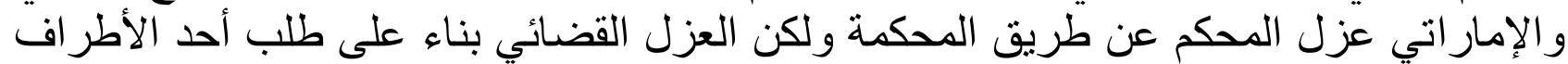

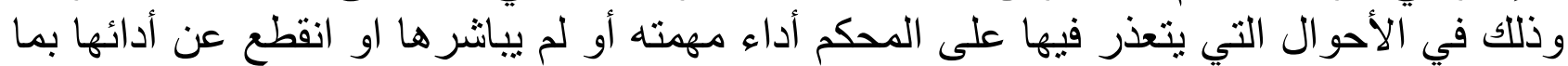

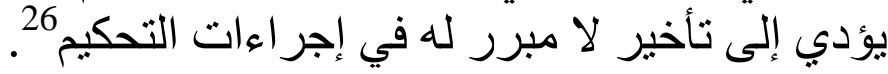

\section{خامسا: دور القاضي في اتخاذ التدابير المؤقتة أو التحفظية:}

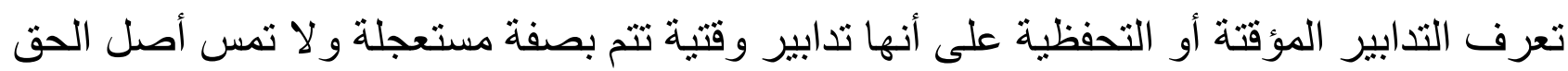
وتكون في صورة طلب تحفظي للحفاظ على إمكانية تنفيذ الحق في المهابة المستقبل أو طلب مستعجل لتنفيذ مصلحة آنية للطالب أو حمايتهاتئ.

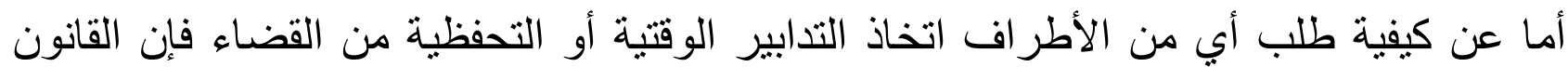

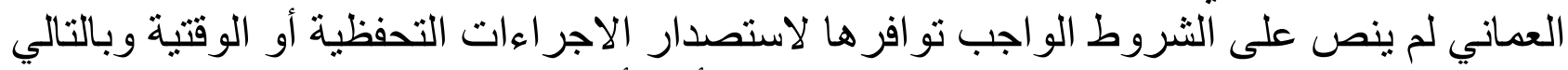

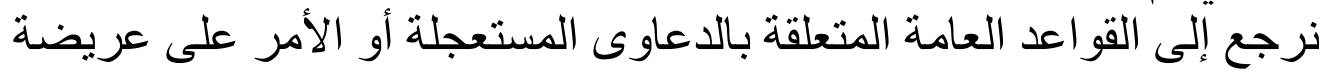

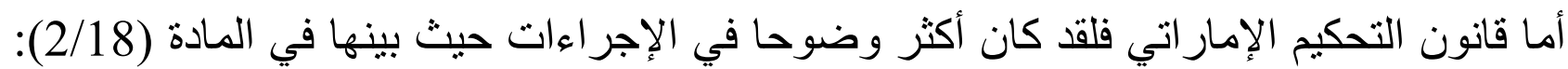

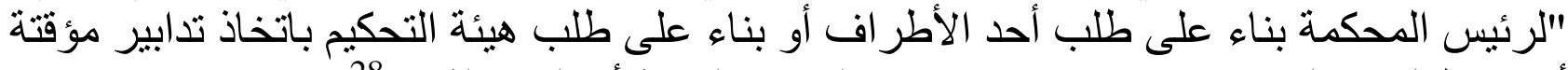

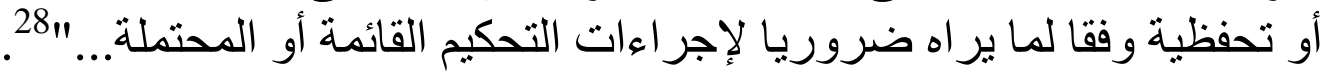

المبحث الثاني: مرحلة ما بعد صدور حكم التحكيم

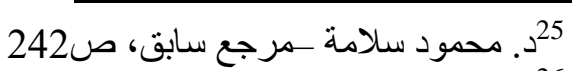

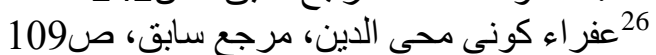

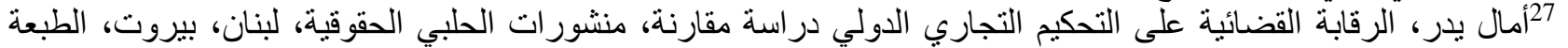

28 أقانون التحكيم الإمار اتي، مرجع سابق 


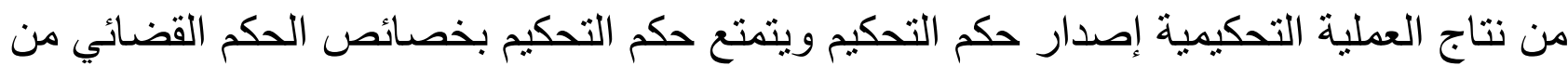

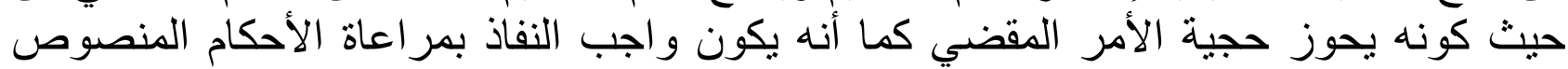
عليها في القانون فلابد أن يخضع حكم التحكيم للرقابة من قبل القضاء وذلكي اللك من أجل التيقن من مر اعاة حكم التحكيم ولذلك أوجدت التشريعات السبل التي يمكن من خلالها بسط رقابتها على حكم التحكيم و هي ذاتها التي جعلت للقضاء دورا مباشرا في التحكيم في مرحلة ما بعد صدور حكم التحكيم.

\section{المطلب الأول: أسباب بطلان حكم التحكيم حسب القانون العماني والإماراتي}

\section{البطلان لاختلال الثروط الموضوعية}

عرفت الفقرة الأولى من المادة (125) من قانون المعاملات المدنية العماني بقولها" العقد الباطل هو العقد غير المشروع لا بأصله و لا بوصفه بأن اختل ركنه أو محله أو

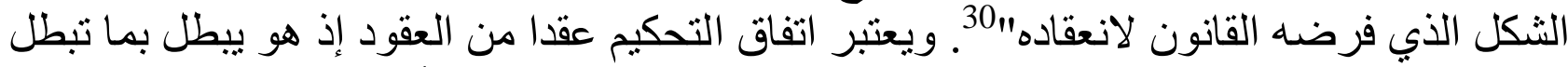

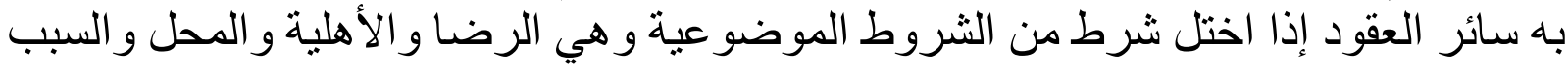
أولا: الرضا: لابد من الحديث أولا عن مفهوم الرضا لدى فقهاء القانون، فالتر اضي و الرضا إذن فأن

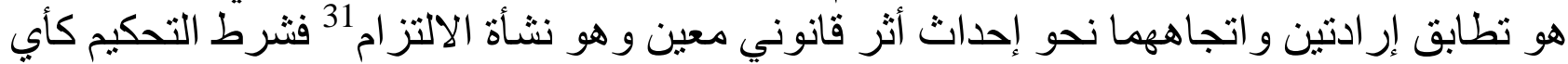

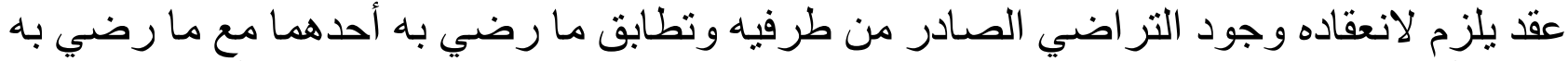

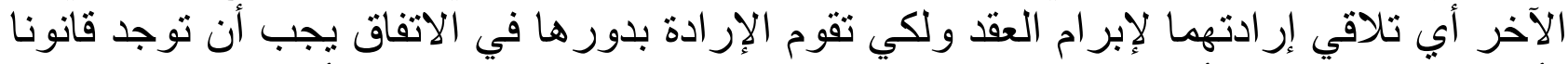

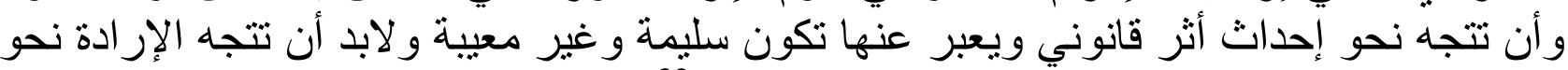

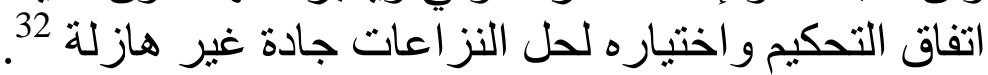

ويشترط لصحة التر اضي على اتفاق التحكيم أن يكون صادرا من شخص ذي أهلية وأن بكون

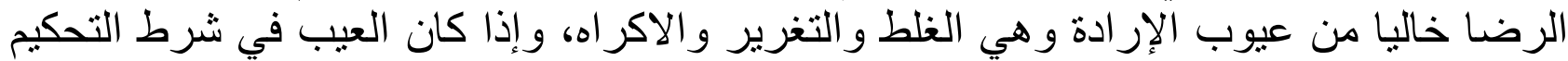

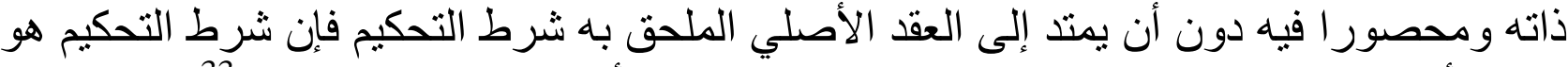

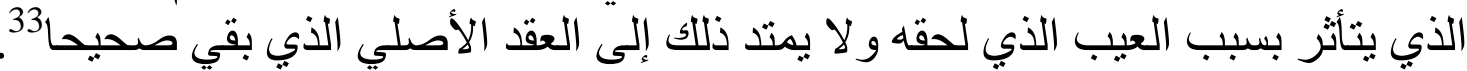
ثانيا: نقص الأهلية وانعدامها: نصت الـمادة (11) و المادة (10) من قانوني التحكيم العماني

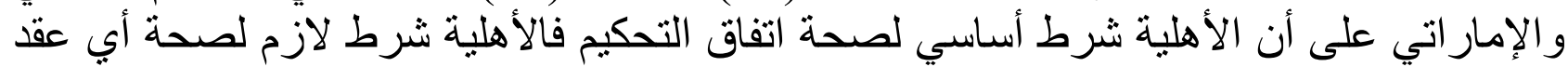

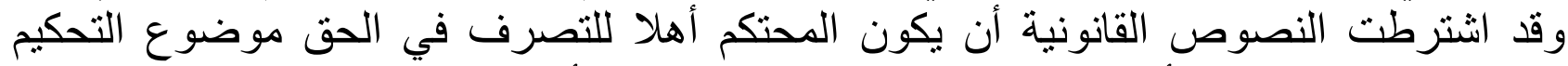

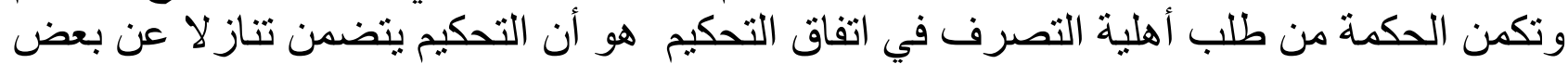

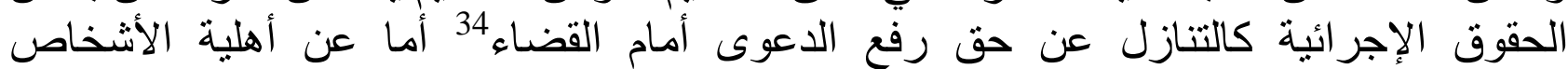
الاعتبارية كالثركات المدنية والتجارية العامة و الخاصة والية والهيئات و المؤسسات العامة فيتعين التحقق من اكتساب واستيفاء الشروط التي يستلزمها القانون للإقرار بالثخصية الاعتبارية فيلزم

29. أ.د. حفيظة السيد الحداد، الرقابة القضائية على أحكام التحكيم بين الازدو اجية والوحدة، دار الفكر الجامعي2003، ص6-293-7

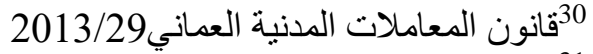

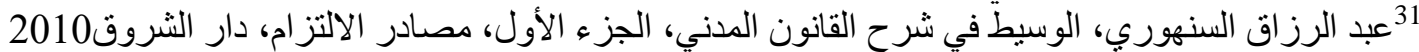

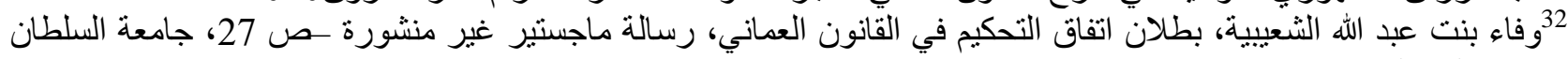

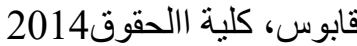

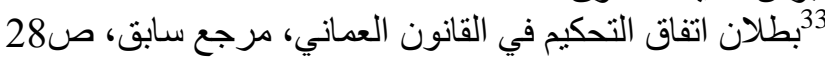
34.د. أحمد بشير الثرايري، بطلان حكم التحكيم ومدى رقابة محكمة النقض (التميز)عليه، دار الثقافة ـعمان ـالطبعة 


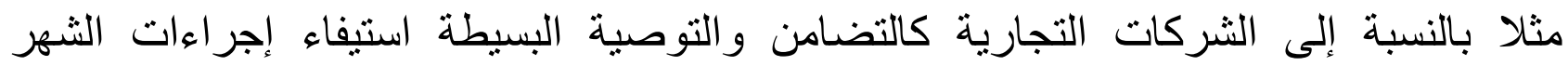

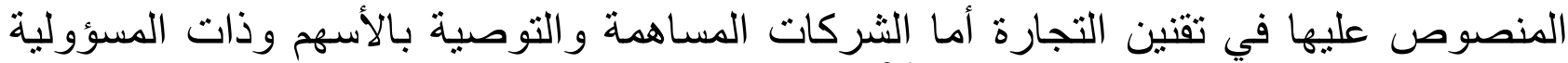
المحدودة فيلزم قيدها في السجل التجاري. التهاري.

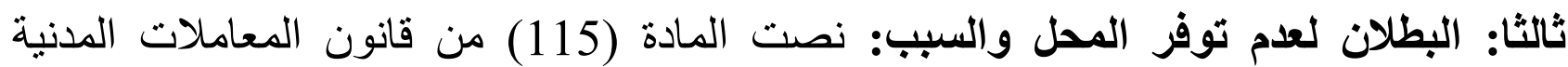

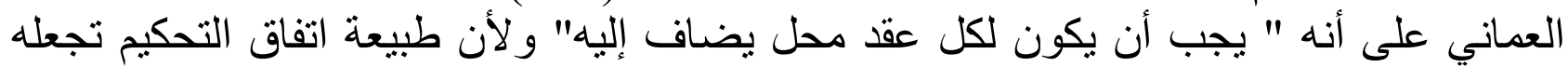

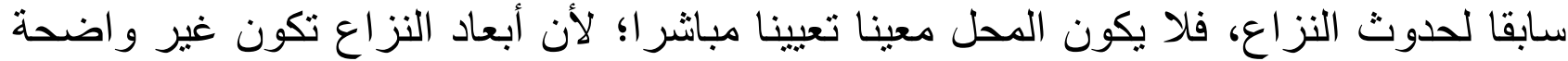

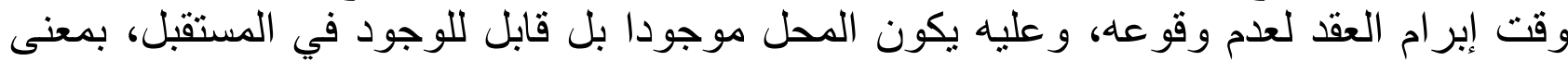

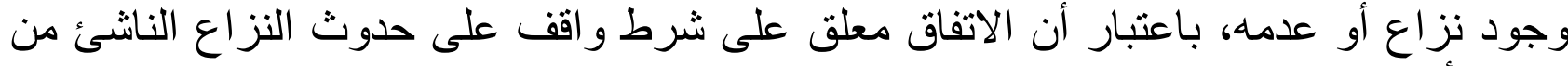

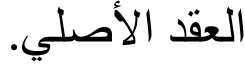

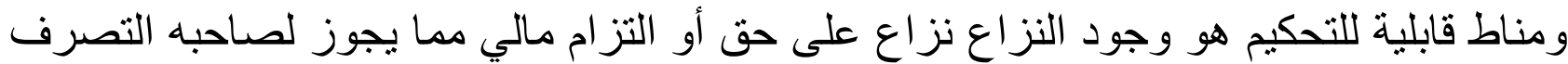

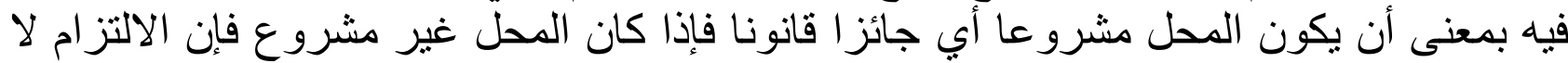

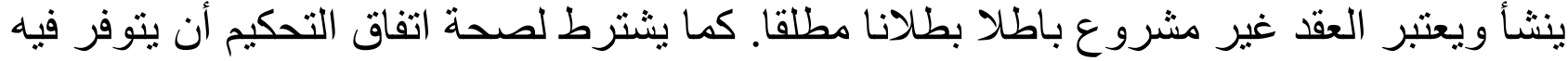

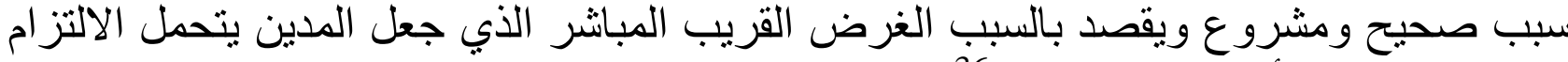
ويشتر طيه فيه دائما أن يكون موجو ودودا. 36

البطلان لتخلف الثروط الثكلية:

مما يميز اتفاق التحكيم هو الثكلية التي سارت عليها معظم التشريعات ومنها قانون التحكيم

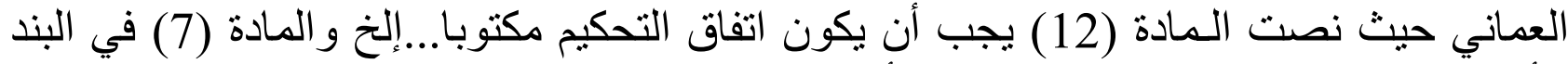

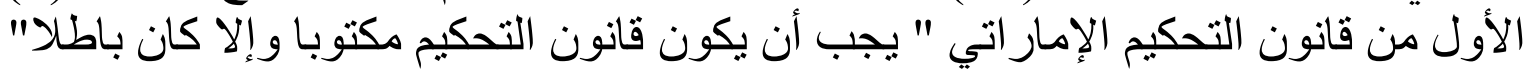

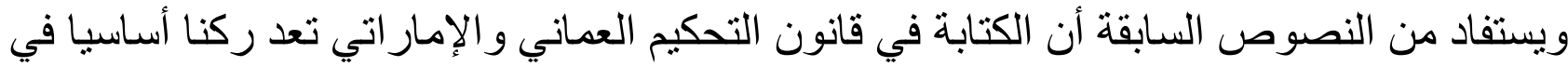

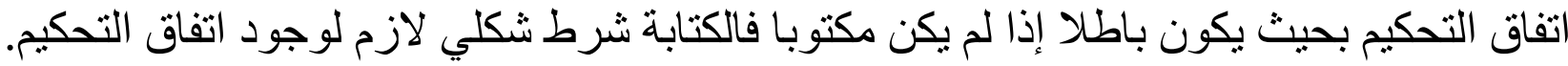

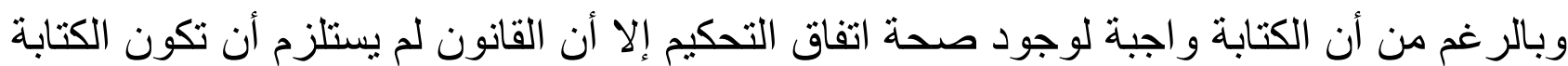

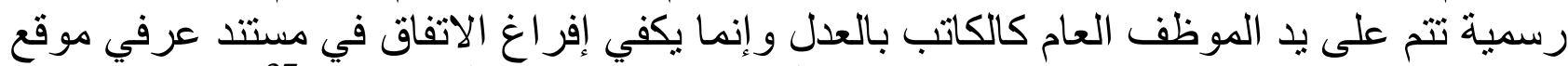

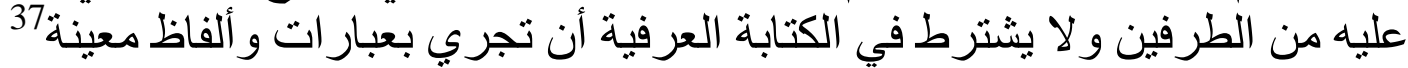
المطلب الثاني: دور القاضي في دعوى البطلان:

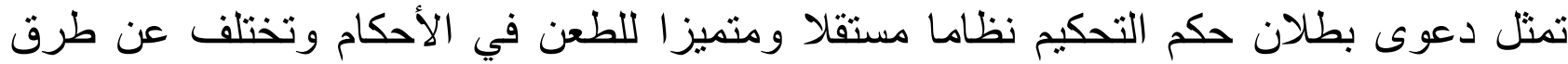

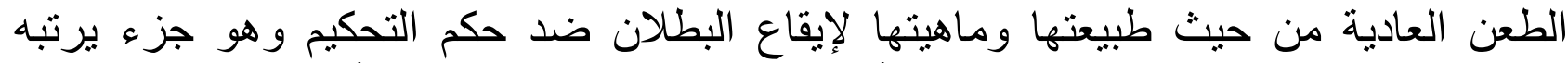

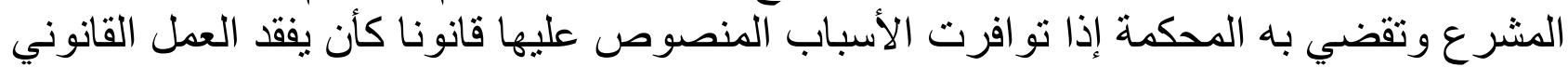

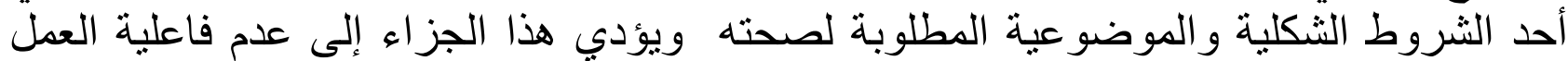

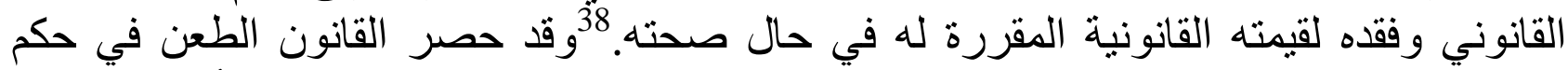

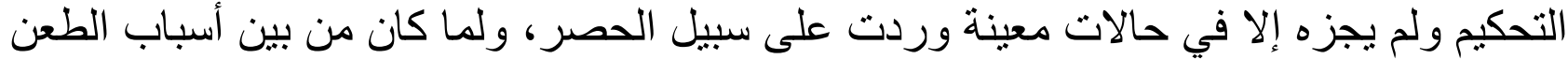

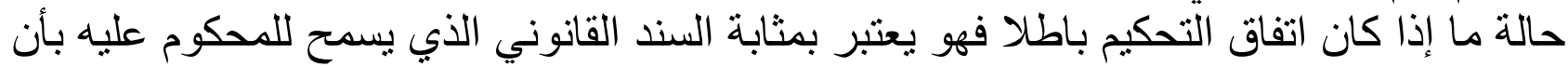

35

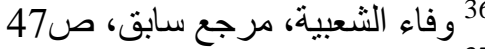

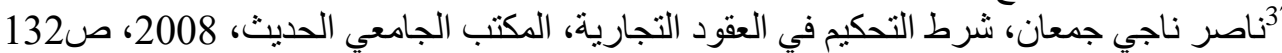

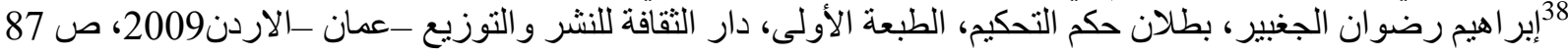


يطالب بإعادة النظر فيما قضي به عليه فجاء الطعن كوسيلة لفرض الرقابة القضائية على أحكام المحكمبن.

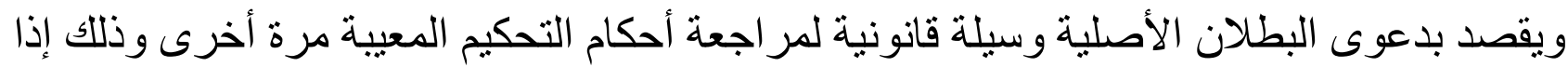

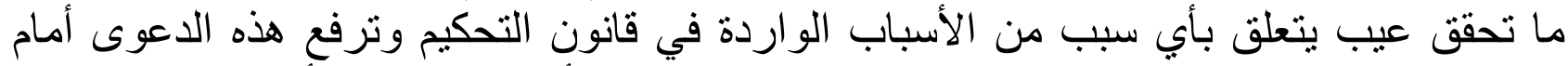

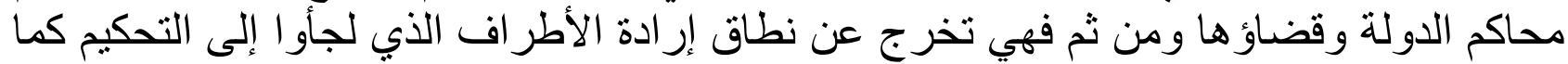

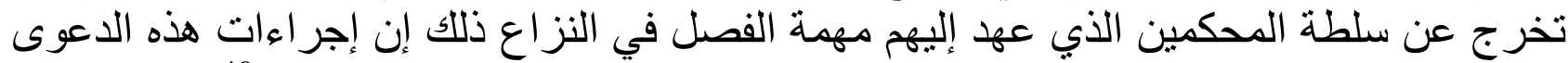

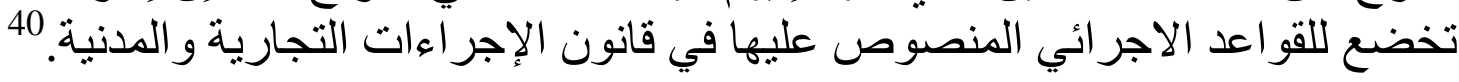
شروط رفع دعوى البطلان أولا. توفر شرط المصلحة القائمة المشروعة: لابد لإقامة دعوى دوعل بطلان حكم التحكيم من تو افر

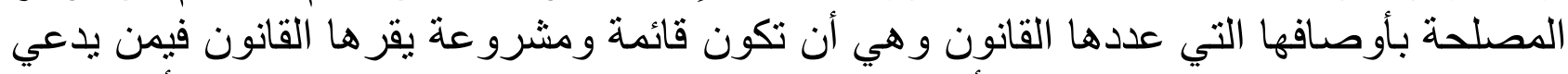

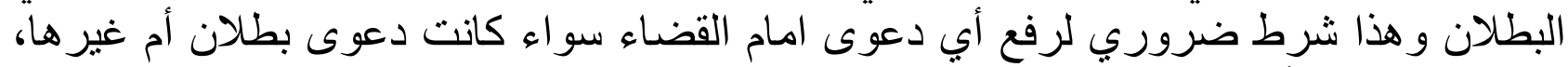

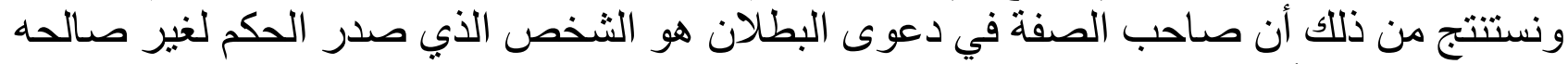

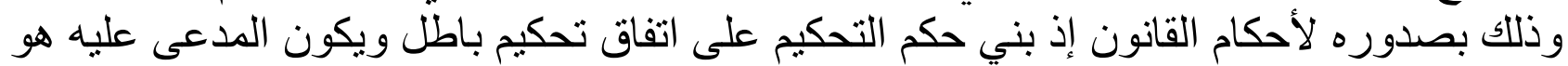

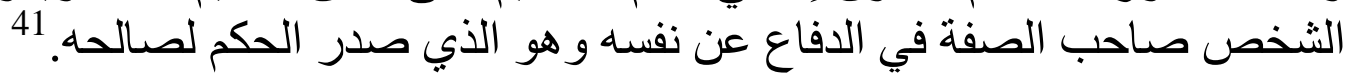

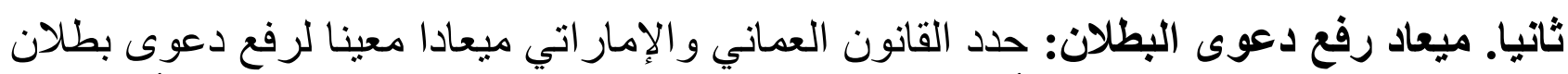

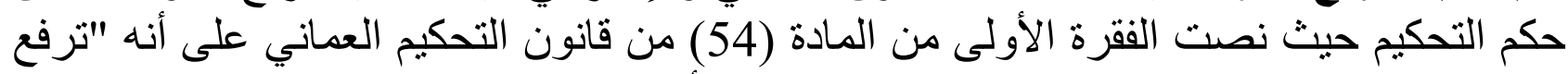

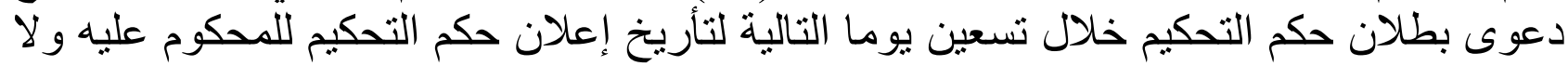

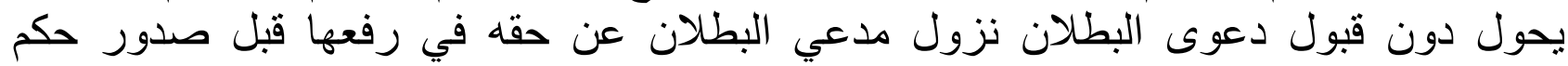

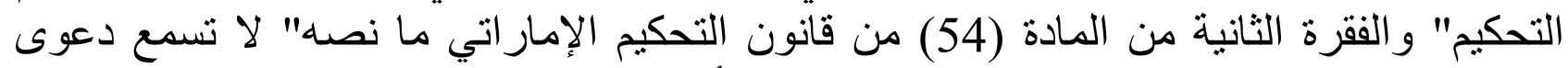

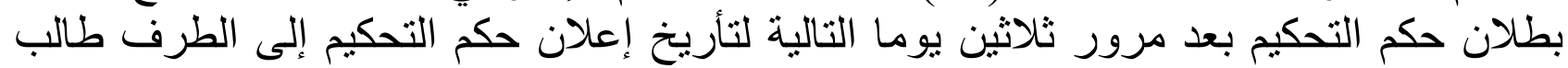

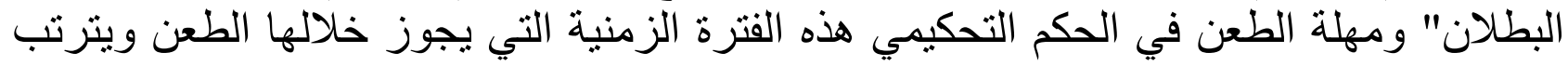
على عدم مر اعاتها سقوط الحق في في الطعن كذللك جو از التهن التفيذ.

ثالثا. المحكمة المختصة بنظر دعوى البطلان: أشتار القانون العماني وبشكل صرئ صريح إلى المحكمة

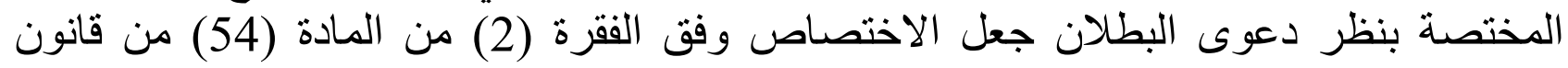

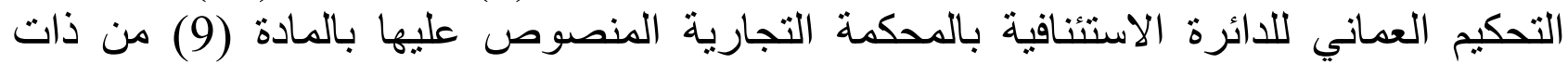

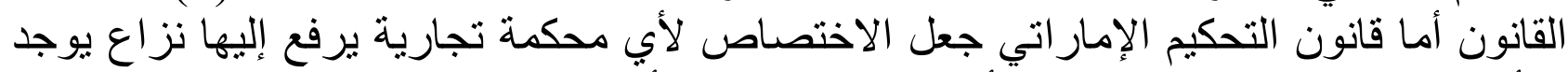

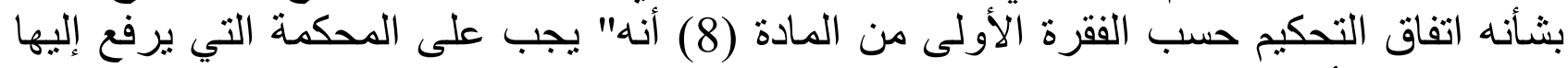

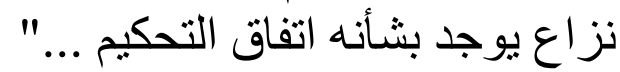

رابعا. توافر سبب من أسباب بطلان اتفاق التحكيم: وضع المشرع العمانه العاني الإماراتي أسبابا

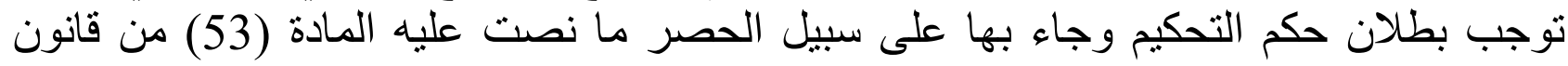
التحكيم الإمار اتي المادة (53) كذللك من قانون التحكيم التحكيم العماني.

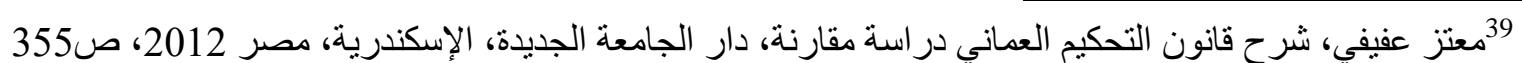

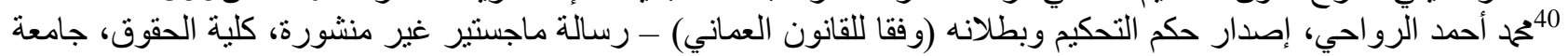

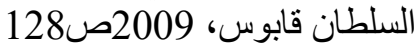

82 
جاءت هذا الدر اسة حول طبيعة الرقابة القضائية على أعمال المحكمين صور ها وحدودها، وتفعيل

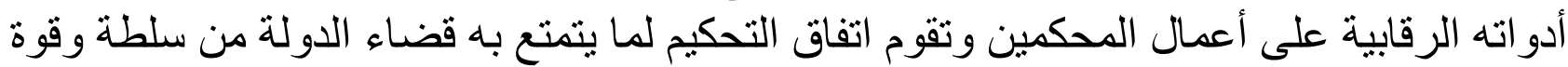

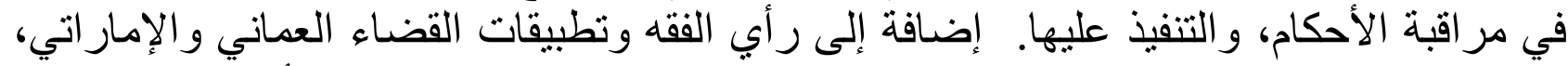

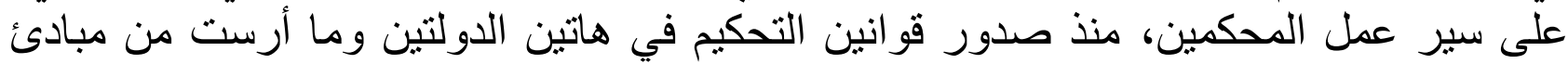
قضائية. وفيما يأتي أهم النتائج التي توصلت منئ إليها الدر اسة:

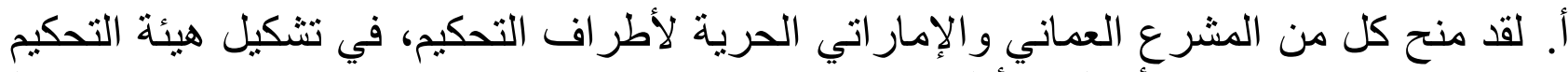

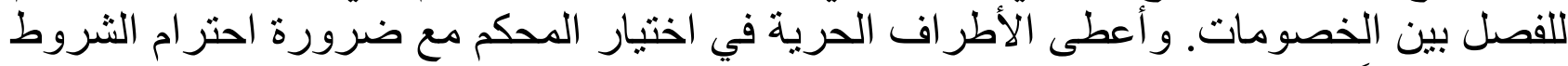
ل اللازمة قانوناً.

ب. تتمتع هيئة التحكيم بخصوصية، إلا إن هذه الخصونة الخصوصية والاستقلال محكومان بالإطار

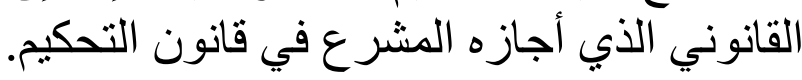

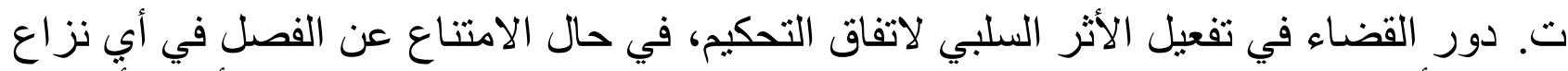

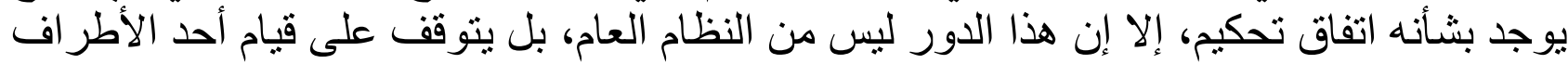

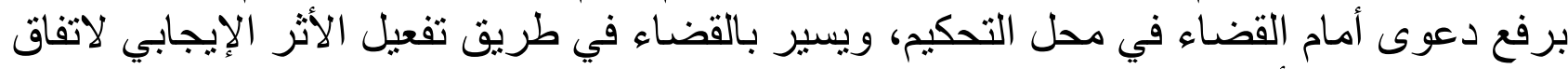
التحكيم القائم بين أطر اف النماء النزاع.

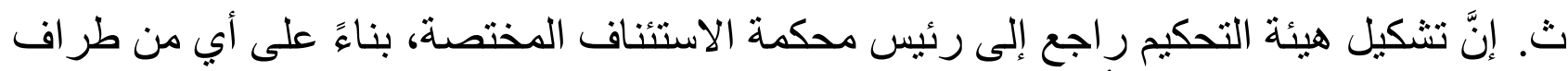

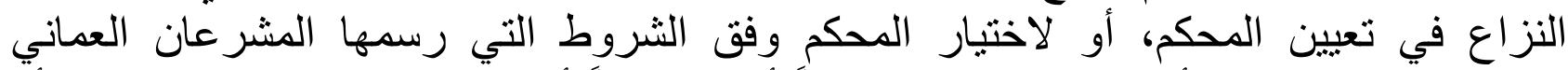

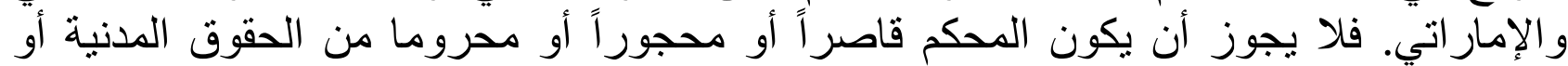
محكوما عليه بجناية أو جنحة. ج. يظهر دور القاضي جلياً في رد المحكمين وفق الإجراءات التي التهاء ذكر ها قانونا التحكيم العماني

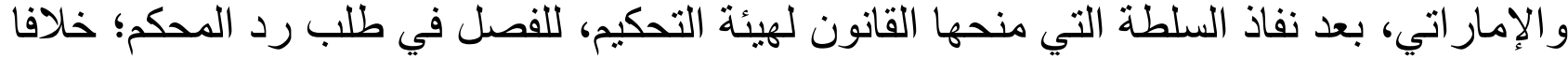

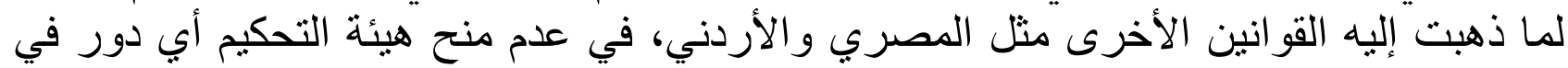

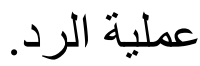
ح. يتوقف عزل المحكم واتخاذ الإجراءات الوقتية والتحفظية، والحصول فئل على التى أدلة الإثبات في

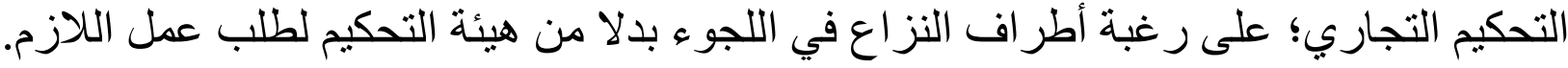

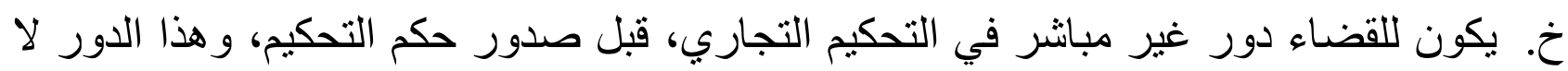

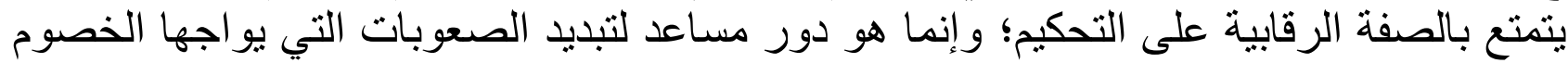
أثناء خصومة التحكيم.

قائمة المراجع:

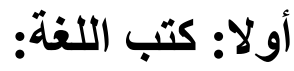

الفيروز أبادي، 2010. القاموس المحيط. بيروت، لبنان: دار الكتاب العربي. 
ثانيا: القوانين:

قانون التحكيم العماني 96/47 2018/6 قانون التحكيم الإمار اتعماني 2013/29 قانون المعاملات المدنية العماني المارتي ثالثا: مراجع القانون:

إبر اهيم رضو ان الجغبير-بطلان حكم التحكيم- الطبعة الأولى-دار الثقافة للنشر والتوزيع -عمان الاردن2009

أحمد بشير الثر ايري- بطلان حكم التحكيم ومدى رقابة محكمة النقض (التميز)عليه-دار التقافة ـ عمان -الطبعة الثانية2016

أحمد عبد الكريم سلامة، قانون التحكيم التجاري الدولي و الداخلي تنظير وتطبيق مقارن، الطبعة

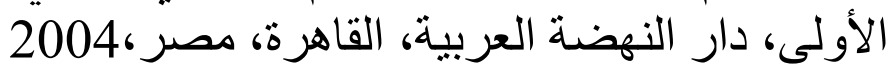

آمال يدرن الرقابة القضائية على التحكيم التجاري الدولي (دراسة مقارنة)، الطبعة الأولى، منشور ات الحلبي الحقوقية، الحنة 2012

حفيظة السيد الحداد_الرقابة القضائية على أحكام التحكيم بين الازدواجية والوحدة-دار الفكر الجامعي2003

الدكتور فتحي والي_قانون التحكيم في النظرية والتطبيق_منشاة المعارف_الإسكندرية_الطبعة الأولى فئ2007.

عامر فتحي البطانيةـ دور القاضي في التحكيم التجاري الدولي در اسة مقارنة_دار الثقافة بعمان الأردن - الطبعة الأولى 2009

عبد الرزاق السنهوري، الوسيط في شرح القانون المدني-الجزء الأول-مصادر الالتزام-دار الثروق2010

محمود سلامة_ الموسوعة الثاملة في التحكيم-الطبعة الأولى_دار مصر للموسوعات المصريةـ القاهرة -مصر 2007.

معتز عفيفي-شرح قانون التحكيم العماني دراسة مقارنةـ دار الجامعة الجديدة_الإسكندرية_مصر 2012

ناصر ناجي محمد جمعان، شرط التحكيم في العقود التجارية، المكتب الجامعي الحديث،

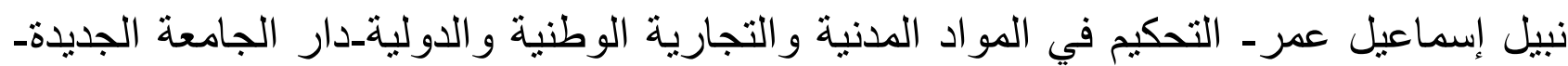

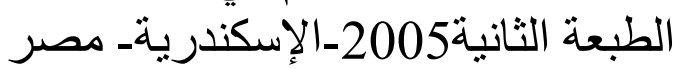
رابعا: الرسائل الجامعية: سلام توفيق حسين-بطلان حكم التحكيم (دراسة تحليلية مقارنة) - رسالة ماجستير غير منشورة-

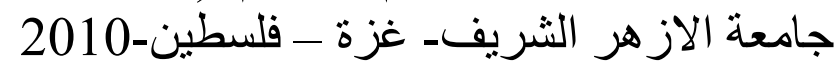


عفر اء كوني محي الدين كونحي- دور القضاء الوطني في التحكيم التجاري الداخلي- رسالة ماجستير غير منشورة

حمد أحمد الرواحي-إصدار حكم التحكيم وبطلانه (وفقا للقانون العماني) - رسالة ماجسنير غير منشورة-كلية الحقوق-جامعة السلطان قابوس-2009

وفاء بنت عبد الله الثعيبية- بطلان اتفاق التحكيم في القانون العماني (دراسة مقارنة) - رسالة

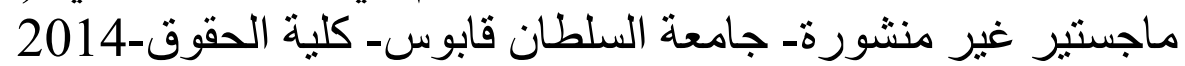

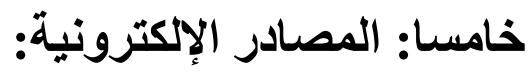

عبد الله السوفاني، الرقابة القضائية على هيئة التحكيم: در اسة مقارنة، بحث منور عبر الإنترنت: http://repository.aabu.edu.jo/jspui/

\section{ARABIC REFERENCES IN ROMAN ALPHABET}

Alfiruz 'Abadi, 2010. Alqamus Almahaytu. Bayrut, Lubnan: Dar Alkitab Alearabi.

'librahim Ridwan Aljaghbir-Btlan Hakam Altahkim- Altabeat Al'uwla-Dar Althaqafat Lilnashr Waltawzie -Eman -Alardn2009

'Ahmad Bashir Alsharayri- Butlan Hakam Altahkim Wamadaa Raqabat Mahkamat Alnaqd (Altmyz)Elyh-Dar Althaqafat -Eman -Altabeat Althanyt2016

'Ahmad Eabd Alkarim Salamat, Qanun Altahkim Altijariu Alduwalia Waldaakhiliu Tanzir Watatbiq Muqarin, Altibeat Al'uwalaa, Dar Alnahdat Alearabiati, Alqahirat, Masr,2004

Amal Yudarun Alraqabat Alqadayiyat Ealaa Altahkim Altijarii Alduwalii (Drasat Mqarn), Altabeat Al'uwlaa, Manshurat Alhalbii Alhuquqiati, 2012

Hafizat Alsyd Alhdad-Alraqabat Alqadayiyat Ealaa 'Ahkam Altahkim Bayn Alaizdiwajiat Walwahdata-Dar Alfikr Aljamey2003

Fathi Walya-Qanun Altahkim fi Alnazariat Waltatbiqa-Mnashat Almearf-Al'iiskndryt-Altbet Al'uwlaa2007.

Eamir Fathi Albtanyt- Dawr Alqadi fi Altahkim Altijarii Alduwalii Dirasat Muqarnt-Dar Althaqafat Bieamman Al'urduni - Altibeat Al'uwlaa2009

Eabd Alrazzaq Alsanhuri, Alwasit fi Sharah Alqanun Almdani-Aljuz' Al'uwla-Msadir Alaltzam-Dar Alshrwq 2010

Mahmud Salamata- Almawsueat Alshshamilat fi Altahkima-Altbeat Alawla-Dar Misr Lilmawsueat AlmsritAlqahrt -Msr2007.

Muetaz Eafify-Shrh Qanun Altahkim Aleumanii Dirasat Muqarnt- Dar Aljamieat Aljdydt-Al'iskndryt-Msr 2012.

Nasir Naji Muhamad Jumean, Shart Altahkim fi Aleuqud Altijariati, Almaktab Aljamieii Alhdyth,2008.

Nabil 'lismaeil Eumr- Altahkim fi Almawadi Almadaniat Waltijariat Alwataniat Walduwaliti-Dar Aljamieat Aljdydt- Altabeat Althanyt2005-Al'iskndryt- Misr

Salam Tawfiq Hasayn-Btilan Hakam Altahkim (Draasat Tahliliat Muqaran) - Risalat Majstayr Ghyr MnshwrtJamieat Al'azhar Alshryf- Ghazat - Filstin-2010

Eufara' Kuni Muhia Aldiyn Kunahi- Dawr Alqada' Alwatanii fi Altahkim Altijarii Aldaakhili- Risalat Majstayr Ghyr Mnshwrt- Jamieat Alsultan Qabus- Kuliyat Alhuquq 2018

Muhamad 'Ahmad Alruwahay-'lisdar Hakam Altahkim Wabitlanih (Wfaqana Lilqanun Aleamani) - Risalat Majstayr Ghyr Minshurta-Kiliat Alhqwq-Jamieat Alsultan Qabus-2009

Wafa' Bnt Eabd Allah Alshaeibiatu- Batlan Aitifaq Altahkim fi Alqanun Aleumanii (Draasat Muqarn) - Risalat Majstayr Ghyr Mnshwrt- Jamieat Alsultan Qabus- Kuliyat Alhqwq-2014

Eabd Allah Alsuwfani, Alraqabat Alqadayiyat Ealaa Hayyat Althkim: Dirasat Muqarant, Bahath Minwr Eabr Al'intrnt 